Marcelo Faustino Alves

\title{
ESTUDO DO COMPORTAMENTO ELÉTRICO DE DISPOSITIVOS DE POTÊNCIA A PARTIR DA OTIMIZAÇÃO DOS PARÂMETROS DE PROCESSO DE DEPOSIÇÃO DO FILME SIPOS OBTIDO POR LPCVD
}

Dissertação Apresentada à Escola Politécnica da Universidade de São Paulo para a obtenção do Título de Mestre em Engenharia 


\section{Marcelo Faustino Alves}

Faculdade de Tecnologia de São Paulo - 1998

Estudo do comportamento elétrico de dispositivos de potência a partir da otimização dos parâmetros de processo de deposição do filme SIPOS obtido por LPCVD

Dissertação Apresentada à Escola Politécnica da Universidade de São Paulo para a obtenção do Título de Mestre em Engenharia

Área de Concentração: Microeletrônica

Orientador:

Prof. Dr. Nilton Itiro Morimoto 
Este exemplar foi revisado e alterado em relação à versão original, sob responsabilidade única do autor e com a anuência de seu orientador.

São Paulo, 26 de março de 2003.

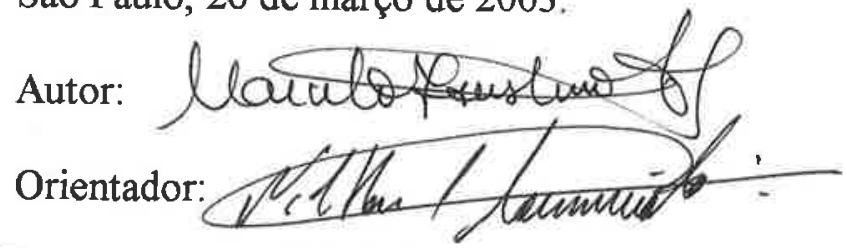

\author{
$B C$ \\ Unlversidade de Sáo Paulo \\ Blblloteted du Escola Politécnica \\ FD- 3368 \\ ted. rev.
}

Alves, Marcelo Faustino

Estudo do comportamento elétrico de dispositivos de potência a partir da otimização dos parâmetros de processo de deposição do filme SIPOS obtido por LPCVD, São Paulo, 2003

Dissertação (Mestrado) - Escola Politécnica da Universidade de São Paulo. Departamento de Engenharia de Sistemas Eletrônicos - Microeletrônica.

1. Introdução 2. Filme SIPOS 3. A produção industrial de dispositivos semicondutores. Escola Politécnica. Departamento de Engenharia Sistemas Eletrônicos II. t 
Dedico este trabatho ao meupai, Paulo Faustino Alves. (in memoriam) 


\section{Agradecimentos}

Ao Prof. Dr. Nilton Itiro Morimoto pela orientação deste trabalho.

Ao Sr. Wanderlei Marzano pelo fornecimento das lâminas contendo os diodos de potência semi-processados.

À Prof. Dra. Ana Neilde Rodrigues da Silva pelas proveitosas discussões e sugestões que valorizaram este trabalho.

Ao Prof. Dr. Luiz da Silva Zambom por seu incomensurável auxílio durante a realização dos experimentos e principalmente pela sua atuante ajuda no desfecho desta dissertação.

Ao Prof. Dr Sebastião Gomes dos Santos Filho por toda sua pronta e importante colaboração nas discussões e sugestões dos resultados das análises obtidas por RBS

Ao Nelson Ordonez e ao Adir Moreira pelo empenho e agilidade na manutenção dos equipamentos dos quais utilizei durante a realização deste trabalho.

Ao meu grande amigo Eduardo Ferreira dos Santos pela sua pronta colaboração durante a minha qualificação.

A Daniela Garrotte Lantin e Edyr Onoda pela sua ajuda na caracterização elétrica dos capacitores MSS; o que contribuiu para enriquecer ainda mais este trabalho.

Ao LAMFI do Instituto de Física da USP, pela realização dos experimentos de RBS.

A minha mãe Maria Aparecida Marcantônio Faustino Alves que me encorajou durante todo este trabalho transmitindo-me carinho, atenção e muita paciência.

Gostaria de agradecer de modo todo especial, ao meu grande amigo Reinaldo de Barros e minha amiga Valderez Teixeira de Castro por todo seu estímulo e confiança. 


\section{SUMÁRIO}

Lista de Figuras

vii

Lista de Tabelas

viii

Lista de Abreviaturas

Lista de Simbolos

Resumo ___ Xi

Abstract_xii

CAPITULO 1

1.0 Introdução

1.1 A passivação superficial em dispositivos de potência

1.2 Materiais utilizados para a passivação dos dispositivos de potência ___ 4

CAPÍTULO 2

2.0 Silicio Policristalino Semi-Isolante (SIPOS)__ ?

2.1 Definição

2.2 Processo de Deposição LPCVD

2.3 Método de Obtenção do Filme SIPOS 10

2.4 Cinética de deposição do Filme SIPOS 11

2.5 Propriedades elétricas do Filme SIPOS

CAPITULO 3

$\begin{array}{lr}3.1 \text { Introdução } & 18\end{array}$

3.2 Fatores que afetam a qualidade dos dispositivos __ 18

3.3 Análise estatística $\quad 21$

3.3.1 Medidas para a caracterização das distribuições ___ 21

3.3.2 Médias e Desvio Padrão _ـ 21

3.3.3 Dispersão Absoluta e Relativa. Coeficiente de Variação (CV) __ 23

CAPÍTULO 4

4.0 Procedimento Experimental __ 24

4.1 Condições Experimentais — 24

4.2 Processo de deposição do filme SIPOS por LPCVD 25

$\begin{array}{ll}4.3 \text { Filmes SIPOS depositados } & 27\end{array}$

4.4 Técnicas de caracterização e equipamentos utilizados neste trabalho ___ 28

CAPÍTULO 5-

5.1.0 Taxa de deposição do filme SIPOS

5.1.1 A influência do espaçamento entre as lâminas na uniformidade em espessura e na concentração de oxigênio presente no filme SIPOS

5.1.2 O comportamento elétrico dos diodos de potência após a etapa de densificação do filme SIPOS_36

5.2.0 Caracterização elétrica dos dispositivos de potência _ 39

5.2. I O efeito da umidade no desempenho elétrico dos diodos de potência __ 45

5.3 Conclusões Finais $\quad 48$

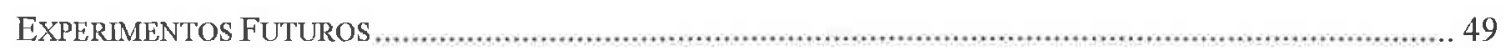

AnEXo 1: Modelamento matématico PRoposto Por Ni E ARNOLD ................................................ 51

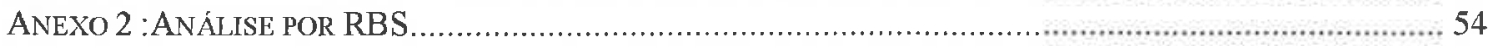

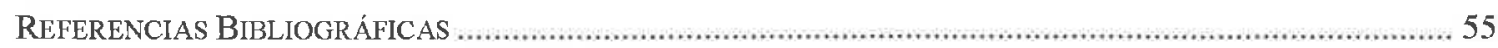




\section{Lista de Figuras}

Figura 1. Comportamento do campo elétrico em diodos obtidos através de tecnologia planar. ...........2

Figura 2. A influência do campo elétrico no raio da região de depleção ...............................................3

Figura 3. (a) O aparecimento de uma corrente pelo filme isolante quando a junção $P / N$ é submetida a um dado potencial elétrico; (b) Efeito negativo provocado pela densidade de cargas no desempenho

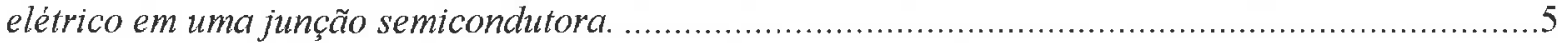

Figura 4. Reator LPCVD utilizado para a obtenção do filme SIPOS. .........................................9

Figura 5. (a) Representação esquemática do modelo proposto por Ni e Arnold.;(b) idealização de uma célula unitária circundada por uma camada de oxido .............................................................13

Figura 6. Modelamento estrutural proposto por Ni e Arnold para o filme SIPOS ............................ 14

Figura 7. Comportamento experimental da condutividade do filme SIPOS em função da concentração de oxigênio obtida no modelo proposto por Ni e Arnold. .................................................... 16

Figura 8. Comportamento experimental da influência da concentração de oxigênio na tensão de

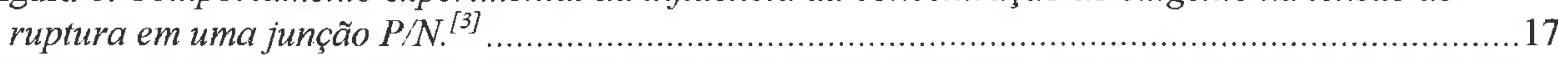

Figura 9. Representação esquemática dos principais tipos de cargas presentes em filmes de oxído de

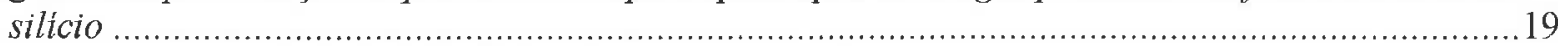

Figura 10. Etapas de processos de um diodo de alta potência .........................................................24

Figura 11. Representação de uma lâmina de silício semi-processada contendo os diodos de potência; fornecida pela Aegis Semicondutores Ltda ................................................................................25

Figura 12. Carregador de quartzo utilizado para a deposição do filme SIPOS bem como a distribuição

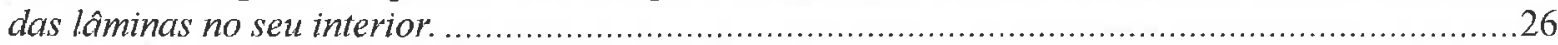

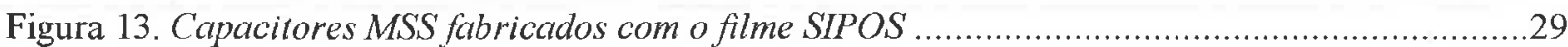

Figura 14. Taxa de deposição do filme SIPOS em função da proporção gasosa $\left(\mathrm{N}_{2} \mathrm{O} / \mathrm{SiH} \mathrm{H}_{4}\right)$..............31

Figura 15. O efeito provocado pelo espaçamento entre as lâminas na uniformidade em espessura no filme SIPOS.

Figura 16. O Espectro RBS das amostras depositadas com diferentes espaçamentos entre as lâminas

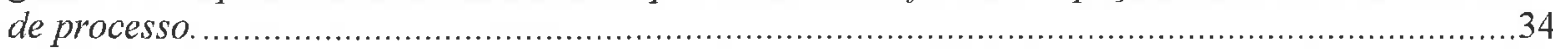

Figura 17. A influência da proporção gasosa $\left(\mathrm{N}_{2} \mathrm{O} / \mathrm{SiH}_{4}\right)$ na concentração de oxigênio presente nos filmes SIPOS depositados.

Figura 18. A influência da proporção gasosa na condutividade elétrica nos filmes depositados nas

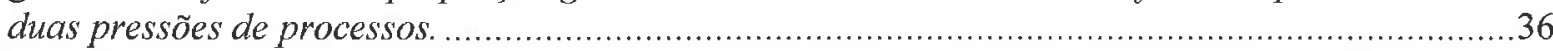

Figura 19. Espectro FTIRS antes e após o processo de densificação das amostras com o filme SIPOS.

Figura 20. Histogramas dos processos de passivação dos diodos de potência com o filme SIPOS. .....39

Figura 21. Histogramas do processo de passivação dos diodos de potência na qual mantivemos fixo o

TPO em 60s e variamos o espaçamento entre as lâminas ...........................................................41

Figura 22. Coeficiente de variação em função do espaçamento entre as lâminas: a) tensão de ruptura;

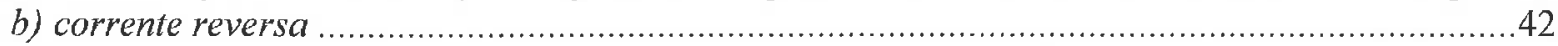

Figura 23. Histogramas dos diodos de potência na qual variamos o TPO em $60 \mathrm{~s}$ e $24 \mathrm{~s}$.................43

Figura 24. Comportamento elétrico dos diodos de potência mantendo-se os mesmos parâmetros de

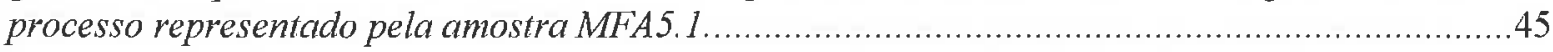

Figura 25. A influência da umidade nas caracteristicas elétricas dos diodos de potência. ..................46

Figura 26. Curvas reversas IxV características dos diodos de potência passivados com o filme SIPOS. 


\section{Lista de Tabelas}

Tabela 1. Valores aproximados da resistividade em diferentes filmes passivantes. .............. 10

Tabela 2. Condições Experimentais utilizadas em nosso trabalho. .................................... 27 


\section{Lista de Abreviaturas}

\begin{tabular}{|c|l|}
\hline CVD & Deposição química a vapor \\
\hline APCVD & Deposição química a vapor em pressão atmosférica \\
\hline PECVD & Deposição química a vapor enriquecida por plasma \\
\hline LPCVD & Deposição química a vapor em baixa pressão \\
\hline RBS & Espectrometria de Retro Espalhamento de Rutherford \\
\hline FTIRS & Espectroscopia por infravermelho com Transformada de Fourier \\
\hline XRD & Difração de raios-X \\
\hline WKB & Wentzel-Kramers-Brillouim \\
\hline EROM & Memória somente para leitura eletricamente alterável \\
\hline MSS & Metal-SIPOS-Silício \\
\hline RCA & Limpeza química padrão \\
\hline
\end{tabular}




\section{Lista de Símbolos}

\begin{tabular}{|c|l|}
\hline$[\mathrm{A}]$ & Concentração do elemento A \\
\hline at. \% & Átomos Percentuais \\
\hline$\sigma$ & Condutividade \\
\hline$\rho$ & Resistividade \\
\hline $\mathrm{I}$ & Corrente elétrica \\
\hline $\mathrm{E}_{\text {sup }}$ & Campo Elétrico Superficial \\
\hline $\mathrm{t}_{\mathrm{dep}}$ & Taxa de deposição \\
\hline $\mathrm{V}_{\mathrm{bl}}$ & Tensão de Bloqueio \\
\hline $\mathrm{V}_{\mathrm{rp}}$ & Tensão de Ruptura \\
\hline $\mathrm{V}_{\mathrm{R}}$ & Tensão reversa \\
\hline $\mathrm{A}$ & Centímetros Cúbicos Padrão por minuto \\
\hline
\end{tabular}




\section{Resumo}

Neste trabalho estudamos o processo de deposição do filme de silício policristalino dopado com oxigênio (SIPOS) depositado por LPCVD, a partir da mistura entre a silana $\left(\mathrm{SiH}_{4}\right)$ e o óxido nitroso $\left(\mathrm{N}_{2} \mathrm{O}\right)$; para a sua aplicação como camada de passivação superficial em dispositivos de potência.

As características físicas e elétricas do filme SIPOS foram analisadas em função dos seguintes parâmetros de deposição: pressão, razão gasosa entre $\left(\mathrm{N}_{2} \mathrm{O} / \mathrm{SiH}_{4}\right)$, espaçamento entre as lâminas de processo, tempo para a formação de uma camada de pré-oxidação entre SIPOS-Si e tempo de processo.

Observamos que o espaçamento entre as lâminas de processo é um importante parâmetro de processo, pois este influi diretamente na uniformidade em espessura e na concentração de oxigênio presente nos filmes depositados.

A caracterização elétrica dos filmes SIPOS foi realizada através de capacitores MSS. Verificamos a validade do modelo sobre o comportamento da condutividade elétrica em função da proporção gasosa $\left(\mathrm{N}_{2} \mathrm{O} / \mathrm{SiH}_{4}\right)$ proposto por Ni e Arnold.

Uma vez determinado as melhores condições de processo, os filmes SIPOS foram depositados sobre diodos de potência pré processados fornecidos pela AEGIS Semicondutores Ltda. Estes diodos foram então caracterizados quanto a sua tensão de ruptura reversa e a sua corrente de fuga reversa.

Os histogramas dos dados experimentais mostraram que diminuindo-se o tempo para a formação de uma camada de pré-oxidação entre a interface SIPOS-Si, temos uma diminuição da corrente reversa que flui pelo filme SIPOS.

Os diodos de potência fornecidos pela Aegis Semicondutores Ltda foram projetados para suportarem uma tensão de ruptura reversa de $650 \mathrm{~V}$. Os diodos passivados com SIPOS suportaram tensões de ruptura de até $1.200 \mathrm{~V}$. 


\section{Abstract}

In this work, the SIPOS (Semi-Insulating Polycrystalline Silicon) LPCVD deposition process was studied to be applied as passivation layer in power devices. It was used a mixture of silane and nitrous oxide to promote the deposition process.

The physical and electrical characteristics were analyzed in function of the follow process parameters: total pressure, gas ratio $\left(\mathrm{N}_{2} \mathrm{O} / \mathrm{SiH}_{4}\right)$, distance between samples in the LPCVD wafer holder; pre oxidation time and total process time.

It was observed that the distance between samples in the LPCVD wafer holder is direct related to the thickness uniformity and in the oxygen concentration present in the SIPOS thin films.

MSS capacitors were fabricated to perform the electrical characterization of the deposited SIPOS films. The validity of the model proposed by Ni and Arnold, to the behavior of the electrical conductivity in function of gas ratio $\left(\mathrm{N}_{2} \mathrm{O} / \mathrm{SiH}_{4}\right)$, was confirmed.

The SIPOS thin film was deposited over pre processed diodes samples, supplied by AEGIS Semicondutores Ltda, in the best process conditions obtained in the previous experiments. The behavior of the leakage current and the breakdown voltage were analyzed.

The histograms of the breakdown voltage data showed that decreasing the pre oxidation time of the SIPOS-Si interface, the leakage current through the SIPOS films decreases.

The power diodes supplied by Aegis Semicondutores Ltda was designed to support a breakdown voltage of $650 \mathrm{~V}$. The power diodes passivated with SIPOS films supported a breakdown voltage up to $1.200 \mathrm{~V}$. 


\section{Capítulo 1}

\subsection{Introdução}

A deposição de filmes de silício policristalino dopado com oxigênio (SIPOS) por LPCVD (Low Pressure Chemical Vapor Deposition), tem sido utilizado para a passivação superficial de dispositivos semicondutores de potência.

Nos últimos 50 anos, o desenvolvimento dos dispositivos semicondutores foi fundamental para o desenvolvimento de sistemas eletrônicos de potência. Assim sendo, desde o advento do diodo, do transistor bipolar e dos tiristores houve uma crescente motivação para o aumento da capacidade de controlar maiores potências destes dispositivos, visando o crescimento do seu campo de aplicação. ${ }^{[1],[2]}$

\subsection{A passivação superficial em dispositivos de potência}

A passivação dos dispositivos de potência é de extrema importância; visto que, possibilita-se fabricar dispositivos semicondutores mais confiáveis e que suportem uma tensão elevada, mantendo-se boa estabilidade elétrica. ${ }^{[1],[2]}$

A limitação da passivação dos dispositivos de potência esta relacionada principalmente a dois fatores, são eles: a uniformidade da junção ${ }^{[1]}$ e o método usado na sua passivação. ${ }^{[1],[2]}$ A uniformidade da junção limita a tensão de ruptura do corpo do dispositivo e o método de passivação determina a tensão de ruptura superficial do dispositivo de potência, a produtividade no que se refere a quantidade de dispositivos aptos para a comercialização. Portanto, a passivação superficial deve ter a capacidade de reduzir ao máximo os efeitos dos estados de superficie e de atenuar os elevados campos elétricos superficiais que ocasionam uma ruptura precoce dos dispositivos de potência. ${ }^{[2],[3]}$ Várias pesquisas tem sido realizadas, onde através do desenvolvimento de vários materiais passivantes tem sido possível diminuir estes efeitos que degradam eletricamente os dispositivos de potência.

Baliga $^{[1]}$ descreve os tipos de tecnologia de terminação de junção, pois esta é a região mais crítica para o desempenho de um dispositivo, e é onde o filme passivante 
interage aumentando o desempenho do dispositivo. A tensão de ruptura de dispositivos de potência reais pode ser reduzida devido a ocorrência de altos campos elétricos no interior do dispositivo ou nas bordas do mesmo, sendo este último o maior problema das industrias de semicondutores.

A tecnologia planar é muito utilizada na fabricação de circuitos integrados e dispositivos de potência. Esta tecnologia se baseia na difusão de dopantes em um semicondutor através de uma máscara de dopagem. ${ }^{[4]}$

A figura 1 exibe uma ilustração de uma junção $\mathrm{P} / \mathrm{N}$ que é formada pela difusão do dopante no semicondutor no qual utiliza-se duas máscaras diferentes: uma retangular e uma circular.

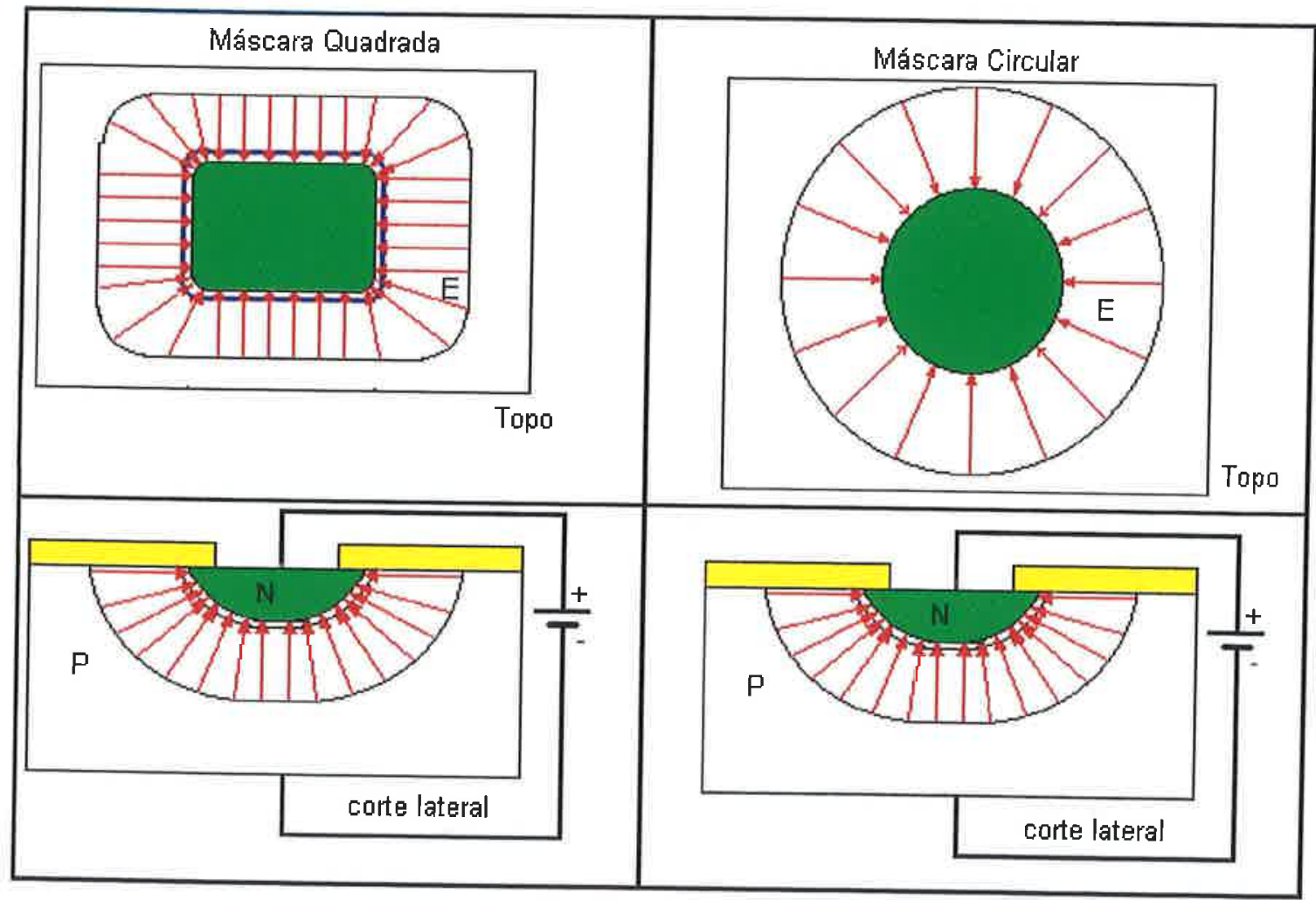

Figura 1. Comportamento do campo elétrico em diodos obtidos através de tecnologia planar.

Quando uma difusão planar é feita em uma máscara retangular, uma junção cilíndrica será formada nos quatro cantos da janela de difusão. Na parte inferior da difusão o campo elétrico é uniforme e a tensão de ruptura é igual em toda essa região. Já nos quatro cantos da junção próximos a superfície as linhas de campo elétrico se acumulam, 
como se pode observar na figura 1 . Isto significa um aumento no campo elétrico nessa região, que reduzirá a tensão de ruptura do dispositivo. ${ }^{[1],[4]}$

Através da figura 1, concluímos que diodos de potência feitos nessa tecnologia devem ser difundidos a partir de máscaras circulares, pois assim eliminamos os cantos agudos onde os campos elétricos superficiais são mais elevados. Mesmo com estes cuidados, a região superficial da junção metalúrgica apresenta um elevado campo elétrico, este problema é descrito e equacionado por Baliga. ${ }^{[1]}$

$\mathrm{Na}$ figura 2, apresentamos o comportamento do campo elétrico na superficie de um diodo difundido em função do raio da região de depleção.

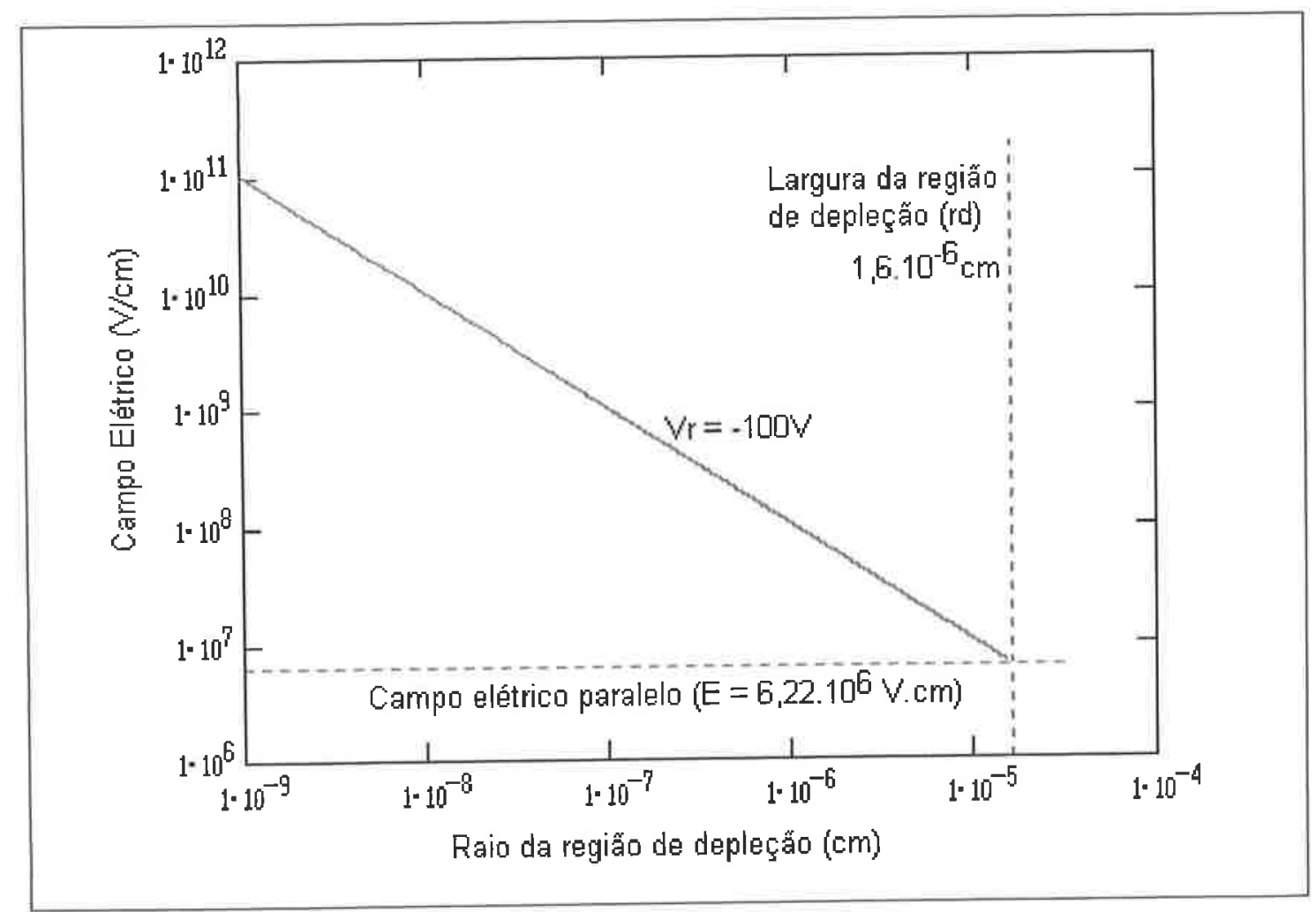

Figura 2. A influência do campo elétrico no raio da região de depleção

Através do gráfico da figura 2 podemos observar que o campo elétrico superficial próximo a junção é muito maior do que o campo paralelo no fundo da junção do diodo.

Como podemos observar os diodos de potência obtidos através de um processo de difusão tem sua tensão de ruptura limitada pelo campo elétrico superficial. Portanto para aumentar o desempenho desses dispositivos quanto a tensão de ruptura devemos nos valer 
de mecanismos que atenuem o campo elétrico superficial.

A primeira é o uso de anéis de campo flutuante, a segunda são as placas de campo, a terceira são os filmes SIPOS e a quarta é a tecnologia de borda inclinada. O objetivo destas quatro técnicas é a mesma, aumentar a região de depleção junto a superfície e assim reduzir o campo elétrico superficial. Assim sendo, para não fugir do objetivo deste trabalho, apresentamos no próximo item alguns filmes passivantes e dentre estes, o filme SIPOS, que são utilizados como camada de passivação superficial em dispositivos de potência.

\subsection{Materiais utilizados para a passivação dos dispositivos de potência}

Dentre os vários materiais passivantes empregados para a passivação dos dispositivos semicondutores, destacam-se:

a) um composto vitreo de $\mathrm{Zn}-\mathrm{B}-\mathrm{SiO}_{2}$ dopado com $\mathrm{Ta}_{2} \mathrm{O}_{5}$ ou $\mathrm{Sb}_{2} \mathrm{O}_{3}{ }^{\left[{ }^{[5]}\right.}$ Este composto vítreo $\left(\mathrm{Zn}-\mathrm{B}-\mathrm{SiO}_{2}\right)$ é obtido através de um processo de eletrodeposição, que consiste na mistura deste composto com uma solução de acetona ou álcool isopropílico; da qual originam-se particulados que ficam em suspensão próximo ao substrato. Estes particulados são depositados sobre o substrato pela passagem de corrente entre o catodo e o substrato. Posteriormente realiza-se uma etapa de densificação para a remoção do solvente, a uma temperatura entre $800^{\circ} \mathrm{C}$ e $900^{\circ} \mathrm{C}$ em ambiente contendo oxigênio. Através deste processo, obtém-se uma camada espessa deste composto em posições seletivas do substrato. Dopando-se o composto vítreo com $\mathrm{Ta}_{2} \mathrm{O}_{5}$, a junção $\mathrm{P} / \mathrm{N}$ torna-se mais estável; entretanto, dopando-se o composto com $\mathrm{Sb}_{2} \mathrm{O}_{3}$ ocorre o incremento da tensão reversa.

A principal limitação deste material passivante é a baixa tensão reversa suportada pelos dispositivos semicondutores fabricados, que é de no máximo 1.000 Volts. $^{[1]}$

b) silicatos $\left(\mathrm{SiO}_{2}\right)$ são filmes de óxido de silício com grandes quantidades de boro e fósforo. A sua principal desvantagem relaciona-se com a sua natureza altamente resistiva. Além disso, é comum encontrarmos neste filme cargas móveis que migram de uma posição para outra ao longo do óxido causando uma instabilidade altamente prejudicial para o dispositivo. As cargas geralmente encontradas neste material são os íons positivos de sódio e potássio. ${ }^{[1],[2],[3]} \mathrm{Um}$ segundo problema do uso de filmes de boro silicato é que esta 
camada não protege o substrato da contaminação iônica e do acúmulo de cargas eletrônicas. As cargas elétricas induzem cargas de polaridade oposta na região da interface filme/substrato, e desta forma, altera-se as propriedades elétricas superficiais dos dispositivos, o que ocasionará a ruptura precoce ou a redução da vida útil do dispositivo. ${ }^{[6]}$

Um outro efeito negativo relacionado ao filme de óxido de silício é a injeção de elétrons quentes no filme passivante (figura 1).

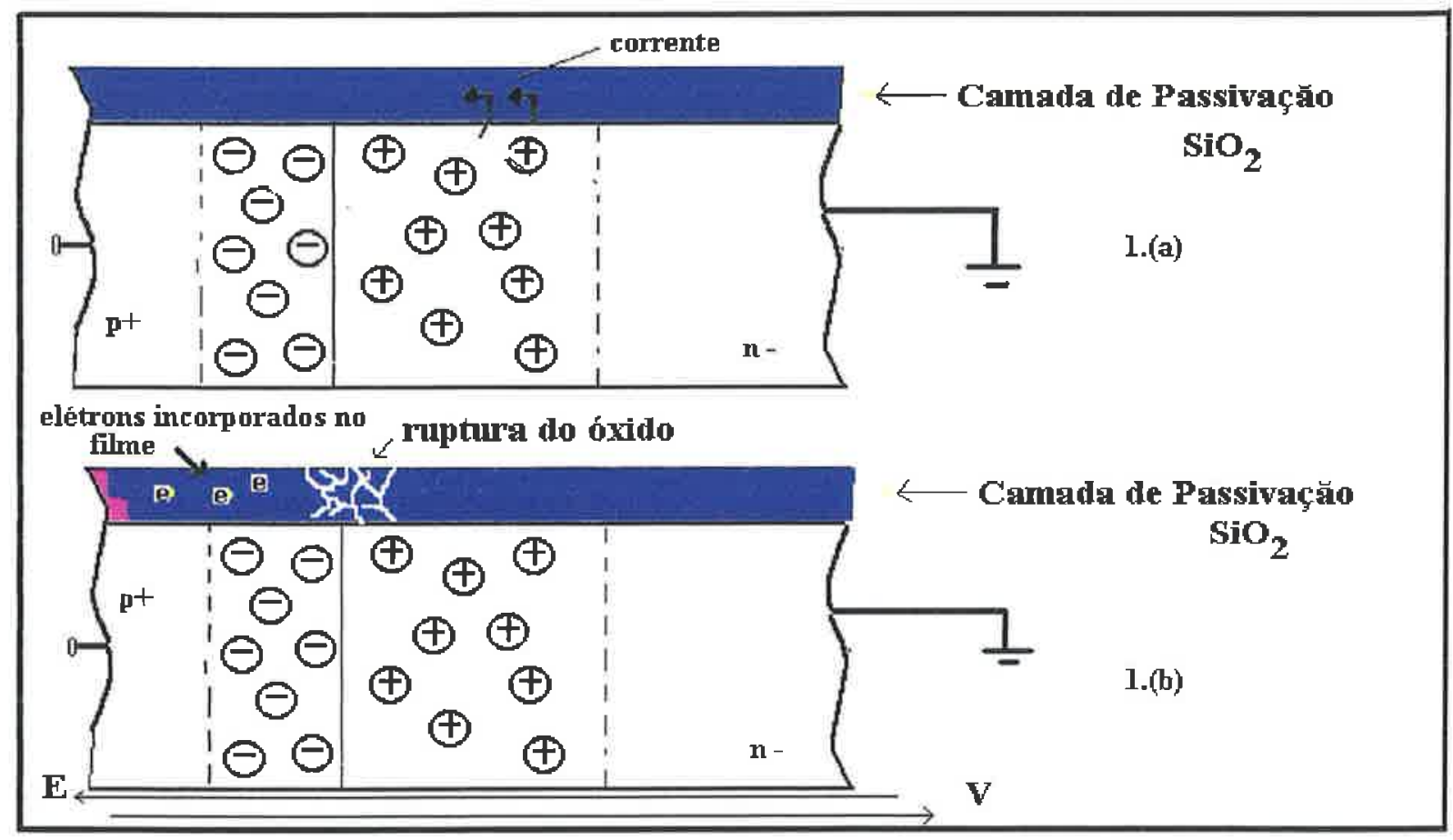

Figura 3. (a) O aparecimento de uma corrente pelo filme isolante quando a junção $P / N$ é submetida a um dado potencial elétrico; (b) Efeito negativo provocado pela densidade de cargas no desempenho elétrico em uma junção semicondutora.

$\mathrm{Na}$ figura 3(a) representamos esquematicamente o efeito provocado pelos elétrons quentes provenientes da junção $\mathrm{P} / \mathrm{N}$ quando são atraídos por um potencial elétrico. Através do potencial aplicado sobre a junção, os elétrons adquirem energia suficiente para atravessar a barreira de potencial imposto entre o filme de óxido de silício e o substrato de silício originando uma corrente através do filme. ${ }^{[3],[7],[8]}$ Entretanto, alguns elétrons com uma energia inferior permanecem retidos ao filme, modificando deste modo, a densidade de cargas próxima à região de depleção. Como resultado, a região depletada de cargas tende a diminuir, aumentando assim o campo elétrico junto a interface óxido-silicio. Desta forma, a tensão de ruptura do dispositivo será menor, assim como o seu tempo de vida útil (figura3(b) $)^{[7],[3]}$ Os dispositivos passivados com este material suportam uma tensão de 
ruptura reversa de até $3.000 \mathrm{~V}^{[1]}$

c) a poliamida é um polímero orgânico, também utilizado na passivação dos dispositivos semicondutores ${ }^{[1],[7],[9]} \mathrm{O}$ processo de obtenção deste polímero consiste na remoção de uma determinada região do substrato, por corrosão química e posteriormente preenche-se esta região com a poliamida em uma solução de dimetilacetonamida. Em seguida, o polímero passa por um processo de cura, em ambiente de nitrogênio a uma temperatura de aproximadamente $250^{\circ} \mathrm{C}$. Os dispositivos semicondutores passivados com este polímero orgânico suportam uma tensão reversa de até 5.000 Volts, mantendo-se boa estabilidade elétrica. Para assegurar uma maior estabilidade elétrica dos dispositivos é necessário que os mesmos sejam hermeticamente selados. Uma outra solução mais usual para amenizar os efeitos provocados pela migração de íons é a deposição de uma camada de nitreto de silício sobre a poliamida.

A principal desvantagem deste polímero é que o mesmo só pode ser aplicado em dispositivos de grandes dimensões. ${ }^{[1],[9]}$

Até o momento percebemos que os processos de passivação descritos apresentam alguns fatores que limitam o desempenho elétrico dos dispositivos de potência. Assim sendo, a Sony Corporation ${ }^{[1],[3],[11],[13]}$ em 1975 introduziu o conceito de um filme semiisolante, ou seja, um filme que apresenta uma resistividade intermediária entre o filme isolante (óxido de silício) e o filme condutor. Assim, surgiu o filme de silício policristalino semi-isolante dopado com oxigênio, o filme SIPOS. Este filme é eletricamente neutro por não ser totalmente isolante. A condutividade elétrica do filme SIPOS é modulada através do controle da concentração de oxigênio durante o processo de obtenção deste filme passivante.

A principal vantagem da utilização do filme SIPOS como camada de passivação em dispositivos de potência é sua capacidade de reduzir os altos campos elétricos superficiais junto a interface SIPOS-Si. Esta redução do campo elétrico é causada pelo alargamento da região depletada de cargas junto a interface SIPOS-silício. ${ }^{[1],[3],[10]}$

Além disso, no filme SIPOS, o efeito memória causado pelos portadores quentes que são injetados na junção $(\mathrm{P}+/ \mathrm{N}-)$ através da ruptura por avalanche, não ocorre neste filme. A explicação para esta diferença está relacionada com a natureza semi-resistiva do filme SIPOS, o que impede que tais cargas permaneçam presos no interior do filme durante 
um longo tempo. ${ }^{[3]}$ Consequentemente, a junção semicondutora, quando passivada com o filme SIPOS, suportará em uma maior tensão reversa, e o tempo de vida do dispositivo também será maior. ${ }^{[1],[3]}$

O filme SIPOS é obtido geralmente por técnicas de CVD utilizando-se como gases reagentes a silana e o óxido nitroso. Os dispositivos semicondutores passivados com este filme suportam tensões de ruptura de até $10.000 \mathrm{~V}^{[1],[2],[3],[10],[11]}$ Devido às suas propriedades semi-isolantes, o filme SIPOS tem substituído com sucesso os filmes passivantes dielétricos tradicionais, como resinas, vidros ou óxido de silício na passivação de dispositivos semicondutores de potência. ${ }^{[12]}$ Atualmente, o filme SIPOS é utilizado na fabricação de diodos de potência, ${ }^{[3],[13]}$, em transistores de alta tensão ${ }^{[14]}$ e displays ${ }^{[15]}$, em memórias EROM (eletrical alterable read only memory) ${ }^{[16]}$ e fotocélulas ${ }^{[17],[18]}$.

Na década de 90, Burte $^{[13]}$ e outros pesquisadores, demostraram experimentalmente a possibilidade de realizar a passivação superficial dos dispositivos de potência com o filme SIPOS obtido por LPVCD. Através da correlação entre os parâmetros do processo (razão gasosa, temperatura e tempo de pré-oxidação) e as propriedades físicas elétricas dos filmes depositados. Burte ${ }^{[13],[19]}$, determinou uma condição de processo de deposição com o filme SIPOS que proporcionou obter dispositivos que suportaram tensões reversas superiores a $2.200 \mathrm{~V}$ e corrente reversa na ordem de dezenas de microampéres.

Nos últimos anos, a Aegis Semicondutores Ltda utiliza um polímero orgânico como material passivante sobre os seus diodos de potência. Este polímero orgânico suporta tensões de rupturas reversas de até $2.000 \mathrm{~V}$ e com baixa corrente reversa. Entretanto, é de interesse desta empresa, o desenvolvimento de outros materiais passivantes bem como de outros processos de deposição que propicie um aumento do desempenho elétrico em seus dispositivos de potência. Assim sendo, estabeleceu-se uma parceria entre esta empresa e o grupo de filme finos do Laboratório de Sistemas Integráveis da Escola Politécnica da Universidade de São Paulo (LSI-EPUSP). Competia a empresa, o fornecimento das amostras contendo os diodos de potência. Já o grupo de filmes finos realizaria um estudo para determinar um processo de deposição de um filme de silício policristalino dopado com oxigênio (SIPOS) obtido por LPCVD (Low Pressure Chemical Vapor Deposition), para a sua aplicação como camada de passivação nos diodos de potência. Através da adequação dos parâmetros do processo LPCVD (pressão, razão gasosa $\left(\mathrm{N}_{2} \mathrm{O} / \mathrm{SiH}_{4}\right)$, 
espaçamento entre as lâminas de processo e tempo de pré-oxidação) esperamos aumentar o desempenho elétrico de dispositivos de alta potência da AEGIS LTDA. A meta inicial deste trabalho, é realizar a adequação dos parâmetros de processo do filme SIPOS para a passivação superficial dos dispositivos de potência, de tal forma que estes dispositivos suportem tensões de ruptura reversa maiores e com corrente reversa menores.

Esta dissertação está estrutura em 5 capítulos. Neste primeiro capítulo apresentamos os objetivos e as justificativas deste trabalho.

No segundo capítulo fazemos uma revisão sobre o processo de deposição do filme SIPOS obtido por LPCVD. Neste capítulo, apresentamos a definição do filme SIPOS e as suas propriedades.

No terceiro capítulo descrevemos os fatores que influenciam o rendimento na produção de dispositivos eletrônicos. Além disso, apresentamos uma breve revisão dos conceitos de estatística.

No quarto capítulo descrevemos os procedimentos experimentais adotados para a realização deste trabalho.

No quinto capítulo apresentamos os resultados experimentais sobre a influência dos parâmetros do processo de deposição do filme SIPOS obtido por LPCVD no desempenho elétrico dos diodos de potência.

Ainda neste capítulo apresentamos as conclusões finais e propomos novos trabalhos que complementam os resultados obtidos. 


\section{Capitulo 2}

\subsection{Silício Policristalino Semi-Isolante (SIPOS)}

\subsection{Definição}

SIPOS é o nome genérico dado a filmes finos de óxido de silício não estequiométricos depositado por $\mathrm{CVD}^{[\mathrm{a}]}$; através de reações químicas entre a silana e o óxido nitroso. ${ }^{[3],[13],[15]}$

\subsection{Processo de Deposição LPCVD}

Os filmes finos de silício policristalino dopado com oxigênio (SIPOS) são obtidos através de vários processos de deposição química a vapor, dos quais incluem a deposição na pressão atmosférica (APCVD) ${ }^{[20]}$, em baixa pressão (LPCVD) ${ }^{[13],[21]}$ e enriquecido por plasma (PECVD) ${ }^{[22]}$. Dentre estes, o mais utilizado é o LPCVD por propiciar filmes com alta uniformidade, pureza e economia de processo. ${ }^{[19]}$

Na figura 4, apresentamos o reator de baixa pressão que será utilizado para a realização deste trabalho.

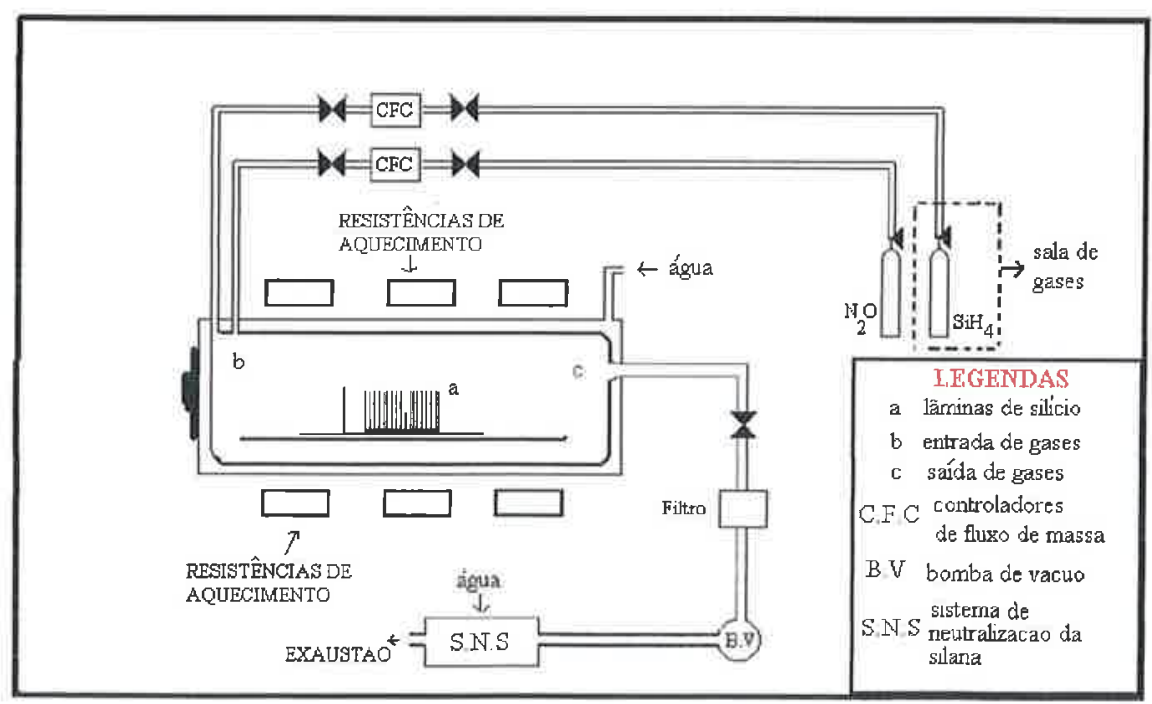

Figura 4. Reator LPCVD utilizado para a obtenção do filme SIPOS.

O reator LPCVD é composto internamente por um tubo de quartzo horizontal,

[a] CVD: A deposição química a vapor é um processo na qual os gases reagentes originam uma fase gasosa; e através de reações químicas próximas ou sobre um dado substrato obtendo-se um filme sólido, não volátil. 
sendo que paralelamente a este tubo existem três regiões, constituídas por resistências, que são responsáveis pelo aquecimento interno do reator. Antes de iniciar-se o processo de deposição do filme, é necessário ajustar a temperatura no reator. Para isso, utiliza-se um termopar tipo K (Alumel/Cromo); ajustando-se a temperatura sempre da parte central do reator para as regiões das extremidades laterais. Este procedimento é utilizado, para garantir a obtenção de uma temperatura de processo constante ao longo do reator, ou seja, para a obtenção de uma planaridade quanto ao perfil térmico.

Os controladores de massa são utilizados para controlar os fluxos dos gases e são auxiliados pela bomba mecânica. Quanto aos gases reagentes, em virtude da silana ser um gás altamente tóxico e explosivo, esta é mantida no cilindro no interior da sala de gases. $\mathrm{O}$ mesmo não ocorre com o oxído nitroso que também é mantido no cilindro, porém este permancece dentro da sala limpa.

Ainda na figura 4, pode-se observar que os gases não reagidos e os subprodutos são retirados do reator pela bomba mecânica e posteriormente são lançados no Sistema de Neutralização da Silana (SNS), este é constituído por um lavador de gases ('scrubber') onde são submetidos à reações de diluição e / ou neutralização com a água.

\subsection{Método de Obtenção do Filme SIPOS}

Neste trabalho o filme SIPOS foi obtido por LPCVD através de reações químicas entre o óxido nitroso e a silana. ${ }^{[3],[13]}$ Através da variação da proporção gasosa destes gases reagentes durante a deposição, podemos obter filmes de silício policristalino com alta resistividade, como observa-se na tabela 1 .

Tabela 1. Valores aproximados da resistividade em diferentes filmes passivantes.

\begin{tabular}{|c|c|}
\hline Filmes passivadores & Resistividade $(\mathbf{\Omega} \mathbf{~ c m})$ \\
\hline Óxido de silício & $10^{14}$ \\
\hline SIPOS & $\mathbf{1 0}^{\mathbf{1 0}}$ \\
\hline $\mathrm{Si}$ - poli não dopado & $10^{5}$ \\
\hline
\end{tabular}

A tabela 1 mostra as resistividades dos filmes de óxido de silício, SIPOS e Silício 
Policristalino. Os filmes SIPOS são considerados semi-isolantes por apresentarem resistividade intermediária entre o filme isolante $\left(\mathrm{SiO}_{2}\right)$ e o filme condutor (Si-poli). Todavia, outros autores ${ }^{[1],[23]}$ utilizam a designação do filme SIPOS como sendo um óxido de silício não estequiométrico $\left(\mathrm{SiO}_{\mathrm{b}}\right)$, onde b pode estar compreendido de zero (Si-poli ) até dois $\left(\mathrm{SiO}_{2}\right)$. Desta forma, pode-se controlar o valor de (b), variando-se a razão gasosa entre os gases reagentes durante o processo de deposição do filme SIPOS. ${ }^{[3],[11]}$

\subsection{Cinética de deposição do Filme SIPOS}

A cinética de deposição do filme SIPOS, pode ser descrita da seguinte forma. Inicialmente, uma parte da silana é adsorvida na superficie do substrato de silício sofrendo as seguintes reações químicas. ${ }^{[24],[25]}$

$$
\begin{gathered}
\mathrm{SiH}_{4 \text { ( gás) }}+\text { sítio superficial }=\mathrm{SiH}_{4 \text { ( adsorvido ) }} \\
\mathrm{SiH}_{4 \text { (adsorvido ) }}=\mathrm{SiH}_{2 \text { (adsovido) }}+\mathrm{H}_{2 \text { (gás) }} \\
\mathrm{SiH}_{2 \text { (liga _se ) }}=\mathrm{Si}_{\text {(sólido) }}+\mathrm{H}_{2 \text { (gás) }}
\end{gathered}
$$

Uma parte do restante da silana irá interagir com o óxido nitroso formando $\mathrm{H}_{2} \mathrm{SiO}^{[24],[25]}$

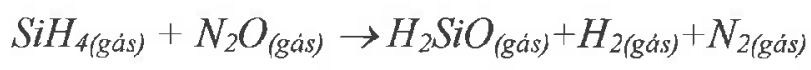

onde temos as seguintes semi-reações:

$$
\begin{aligned}
& \mathrm{N}_{2} \mathrm{O}_{\text {(gás })} \rightarrow \mathrm{O}_{\text {(gás) }}+N_{2(g a \dot{s} s)}
\end{aligned}
$$

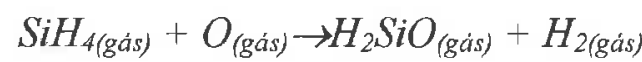

A silana restante irá se decompor em silieno $\left(\mathrm{SiH}_{2}\right)$ e este irá reagir com o óxido nitroso, também formando $\mathrm{H}_{2} \mathrm{SiO}^{[24],[25]}$

$$
\mathrm{SiH}_{2(g a \dot{a} s)}+\mathrm{N}_{2} \mathrm{O}_{\text {(gás) }} \rightarrow \mathrm{H}_{2} \mathrm{SiO} \mathrm{O}_{\text {(gäs) }}+\mathrm{N}_{2(g a \dot{s} s)}
$$

onde temos as seguintes semi-reações:

$$
\begin{aligned}
& N_{2} O_{\text {(gás) }} \rightarrow O_{\text {(gás) }}+N_{2(g a ́ s)} \\
& \mathrm{SiH}_{2 \text { (gás) }}+\mathrm{O}_{\text {(gäs) }} \rightarrow \mathrm{H}_{2} \mathrm{SiO}_{\text {(gáa })}
\end{aligned}
$$


Finalmente o $\mathrm{H}_{2} \mathrm{SiO}$ irá se adsorver na superficie do substrato de silício formando uma ligação Si-O-Si:

$$
\mathrm{H}_{2} \mathrm{SiO}_{\text {(gás) }}+\text { sítio ativo } \rightarrow \mathrm{SiO}_{\text {(sólido) }}+\mathrm{H}_{2 \text { (gás) }}
$$

O equacionamento descrito, exibe a relação existente entre a decomposição do óxido nitroso com a concentração de oxigênio presente no filme SIPOS. Com o aumento do fluxo de óxido nitroso, durante o processo de deposição, ocorre uma diminuição da taxa

de deposição do filme SIPOS. ${ }^{[2]}$ Este comportamento é decorrente do fato de que mantendo-se a mesma vazão de silana e inserindo-se um maior fluxo de óxido nitroso durante o processo de obtenção do filme SIPOS, estamos diminuindo a pressão parcial de silana. Desta forma, estaremos aumentando a concentração de $\mathrm{H}_{2} \mathrm{SiO}$ para a subsequente formação de $\mathrm{SiO}$ com uma taxa menor. ${ }^{[26]}$

\subsection{Propriedades elétricas do Filme SIPOS}

Joubert $P{ }^{[27]}$ demonstrou que os contornos de grão são constituídos por átomos desordenados nos quais encontramos inúmeros defeitos provenientes de ligações incompletas. Já o interior dos grãos são constituídos por átomos ordenados e que mantém a mesma estrutura cristalina. Consequentemente, teremos um coeficiente de difusão maior nos contornos de grão do que no grão de silício, o que implicará em uma maior segregação de impurezas nos contornos de grãos que alteram as propriedades elétricas do semicondutor.

As propriedades elétricas do filme SIPOS são influenciadas diretamente pela concentração de oxigênio presente no filme depositado, causando uma diminuição na condutividade elétrica do filme SIPOS. ${ }^{[3],[14]}$

O modelo proposto por Ni e Arnold ${ }^{[28]}$ procura descrever o comportamento elétrico do filme SIPOS em função da concentração de oxigênio presente no filme depositado. Este modelo admite que cada grão de silício esta circundado por uma camada de $\mathrm{SiO}_{2}$ e por ligações químicas incompletas do tipo $\mathrm{SiO}$.

O modelo proposto por Ni e Arnold é representado esquematicamente, na figura 5. 


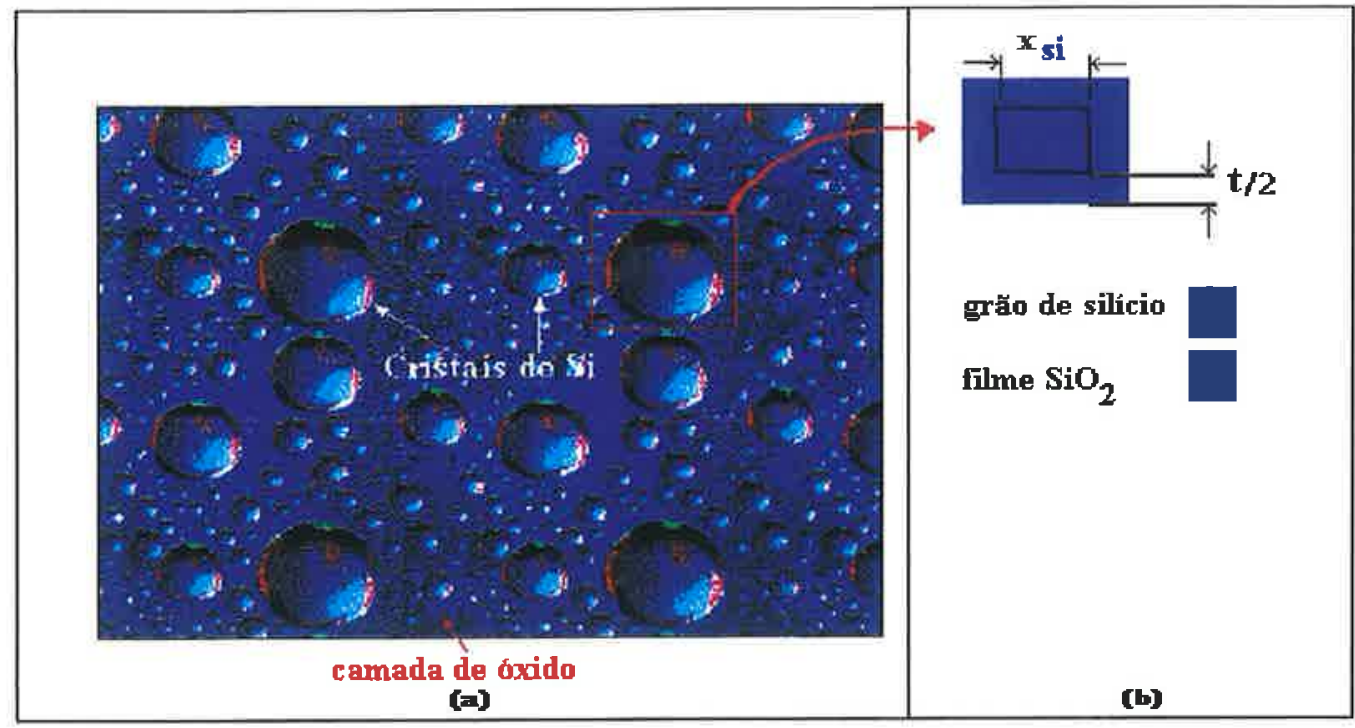

Figura 5. (a) Representação esquemática do modelo proposto por Ni e Arnold.; (b) idealização de uma célula unitária circundada por uma camada de oxido

O modelo proposto por Ni e Arnold ${ }^{[28]}$ é baseado na teoria termodinâmica, onde é esperado que o excesso de oxigênio agregue-se nos contornos de grãos formando as ligações Si-O-Si.

Este modelo proposto por $\mathrm{Ni}$ e Arnold, relata que a concentração de oxigênio presente no filme SIPOS sempre excede a máxima solubilidade sólida quando comparado ao silício. ${ }^{[11],[28]}$ Através da técnica de absorção de infravermelho torna-se possível identificar que a maioria das ligações químicas encontradas no filme é do tipo Si-O, ainda que outras ligações (Si-H e SiOH) também são encontradas nos filmes depositados. ${ }^{[29]}$ Embora seja conhecido que as ligações Si-O são energeticamente mais favorecidas do que as ligações $\mathrm{Si}-\mathrm{Si}$, o número de ligações $\mathrm{Si}-\mathrm{O}$ podem aumentar com o aumento da incorporação de oxigênio ao filme depositado e, conseqüentemente, a espessura média da camada de $\mathrm{SiO}$ também pode aumentar. ${ }^{[11],[28]}$

Assim sendo, este modelo relaciona a concentração de oxigênio presente no filme SIPOS com a espessura média do filme depositado que circunda os grão de silício. Para facilitar o entendimento sobre a influência da concentração de oxigênio na condutividade elétrica do filme SIPOS, idealizou-se uma célula unitária representada pela figura $5 \mathrm{~b}$.

O volume do filme SIPOS pode ser obtido relacionando-se a fração atômica do oxigênio $\left(\mathrm{x}_{0}\right)$ com a fração volumétrica de óxido de silício, conforme pode ser visto pela equação $1^{[28]}$ 


$$
v_{\text {sio } 2}=\left[1+\left(2 \cdot \frac{d_{2} M_{1}}{d_{1} \cdot M_{2}}\right) \cdot\left(\frac{1}{x_{o}}-\frac{3}{2}\right)\right]^{1}
$$

onde $d_{1}$ e $d_{2}$ são as densidades e $M_{1}$ e $M_{2}$ são os pesos moleculares do silício e do óxido de silício.

A espessura da camada deste óxido $\left(\mathrm{t}_{\mathrm{SiO} 2}\right)$ depende diretamente da distância entre cada grão de silício $\left(\mathrm{x}_{\mathrm{si}}\right)$ e do volume do filme depositado $\left(\mathrm{v}_{\mathrm{SiO} 2}\right)$, conforme determinado experimentalmente por Ni e Arnold. ${ }^{[28]}$; equação2:

$$
t_{s o 2}=x_{S i}\left[\left(1-v_{S_{02} 2}\right)^{-1 / 3}-1\right] .
$$

Equação 2

$\mathrm{Na}$ figura 6a, assumi-se que cada grão de silício possui praticamente o mesmo diâmetro, além de que, cada grão ficaria circundado por uma camada de óxido com espessura $t_{\text {Sio2. }}$ Esta camada de óxido é constituída por uma concentração de oxigênio presente nos contornos de grãos, e com o seu aumento, causará um aumento de sua barreira de potencial. Isto implica em uma diminuição da condutividade do filme agregado.

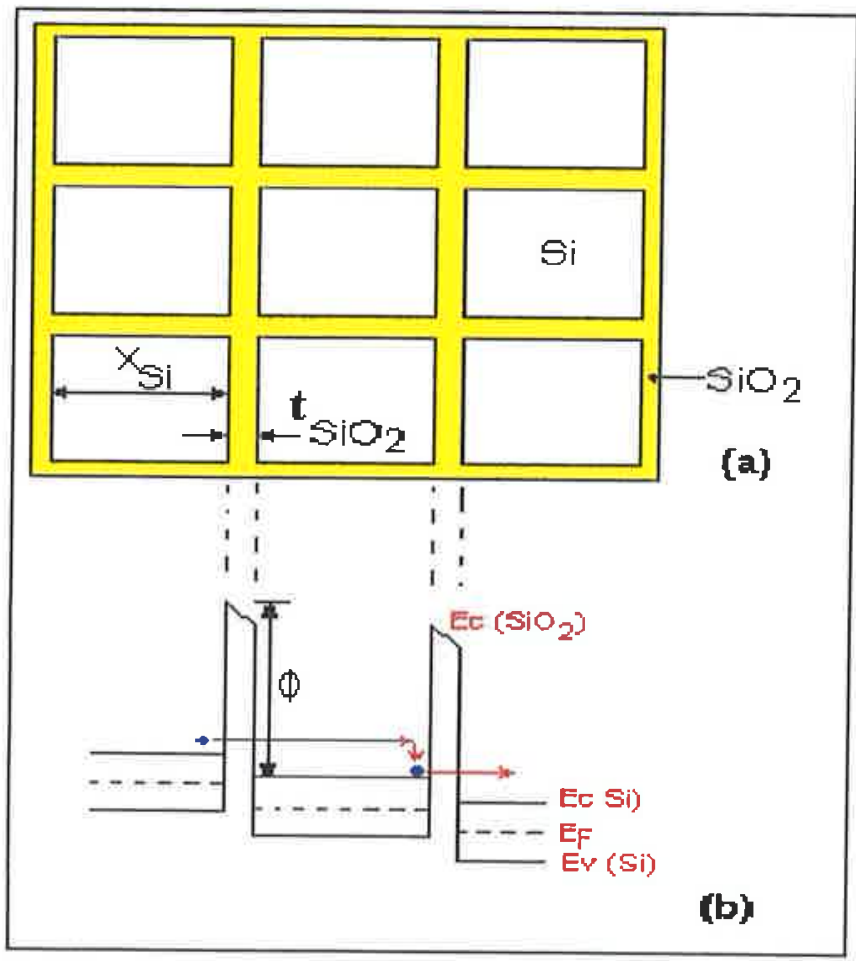

Figura 6. Modelamento estrutural proposto por Ni e Arnold para o filme SIPOS:

(a) microestrutura e (b) diagrama de energia. ${ }^{30}$

$\mathrm{Na}$ figura $6 \mathrm{~b}$, representamos o diagrama de bandas de energias para a representação do modelo, onde Ec é o nível de condução, Ev é o nível de valência e Ef é o nível de 
Fermi.

$\mathrm{O}$ modelo proposto por $\mathrm{Ni}$ e Arnold, relata que em virtude de ocorrer um armadilhamento de cargas nos estados superficiais da interface $\mathrm{Si}_{-} \mathrm{SiO}_{2}$, uma região de cargas espaciais existirá dentro de cada grão de silício (figura 6a). ${ }^{[31]}$ Assim a densidade de estados superficiais $\left(\mathrm{n}_{\mathrm{s}}\right)$ necessária para depletar todo o grão de silício, assumindo-se que o diâmetro do grão é muito menor que o comprimento da largura da região de depleção no grão, é representada na equação 3 :

$$
n_{s} \geq d \frac{\left|N_{d}-N_{n}\right|}{6}
$$

Equação 3

onde $|\mathrm{Nd}-\mathrm{Na}|$ é a diferença entre a concentração de impurezas doadoras e aceitadoras nos grãos de silício. Exemplificando, admitindo-se uma densidade de estados de interface de $10^{12} \mathrm{~cm}^{-2}$, temos energia suficiente para depletar um grão de silício de 0,5 $\mathrm{nm}$ com uma dopagem inferior a $10^{19} \mathrm{~cm}^{-3}$. Assim podemos concluir que a condução é devida ao tunelamento de portadores gerados termicamente entre os grãos de silício, isso se considerarmos que os grãos de silício nos filmes SIPOS são intrínsecos. Na figura 6b, ilustramos uma grande diferença de potencial entre a banda de valência e a de condução no óxido, assim sendo, a corrente total de portadores de cargas em baixos campos elétricos $(0<\mathrm{E}<150 \mathrm{KV} / \mathrm{cm})$ é devido ao tunelamento de portadores.

No anexo 1 apresentamos o equacionamento matemático utilizado por Ni e Arnold que mostra como a espessura da camada de óxido que reveste os grãos de silício influência na condutividade elétrica no filme SIPOS. O resultado deste equacionamento é mostrado na equação 4 :

$$
\sigma_{\text {nétal }}=A \cdot\left(x_{\text {si }}+t_{\text {sio }}\right) \cdot \exp \left(-B \cdot t_{\text {so }}\right) \quad \text { Equação 4, }
$$

onde: A e B são constantes,

$\mathrm{X}_{\mathrm{si}}$ é a diâmetro de cada grão de silício

$t_{\text {sio: }}$ espessura do filme depositado

A equação 4 mostra que para um valor fixo do diâmetro do grão de silício $\left(\mathrm{x}_{\mathrm{si}}\right)$, a 
espessura da camada do óxido que reveste o grão é proporcional à concentração de oxigênio presente ao filme. Deste modo, através deste modelo, espera-se uma redução da condutividade elétrica do filme, a medida em que aumentamos a concentração de oxigênio durante o processo de deposição do filme SIPOS.

A figura 7 representa o comportamento experimental da condutividade elétrica dos filmes SIPOS em função da concentração de oxigênio quando comparado a sua curva teórica. Em seus cálculos Ni e Arnold consideraram um diâmetro de tamanho de grão com $4,5 \mathrm{~nm}$. A inclinação da linha sólida observada nesta figura, corresponde a uma barreira de potencial do óxido $(\phi=3 \mathrm{eV}$ ). Este comportamento exponencial da condutividade em função da concentração de oxigênio é citado em vários trabalhos. ${ }^{[1],[3],[13]}$

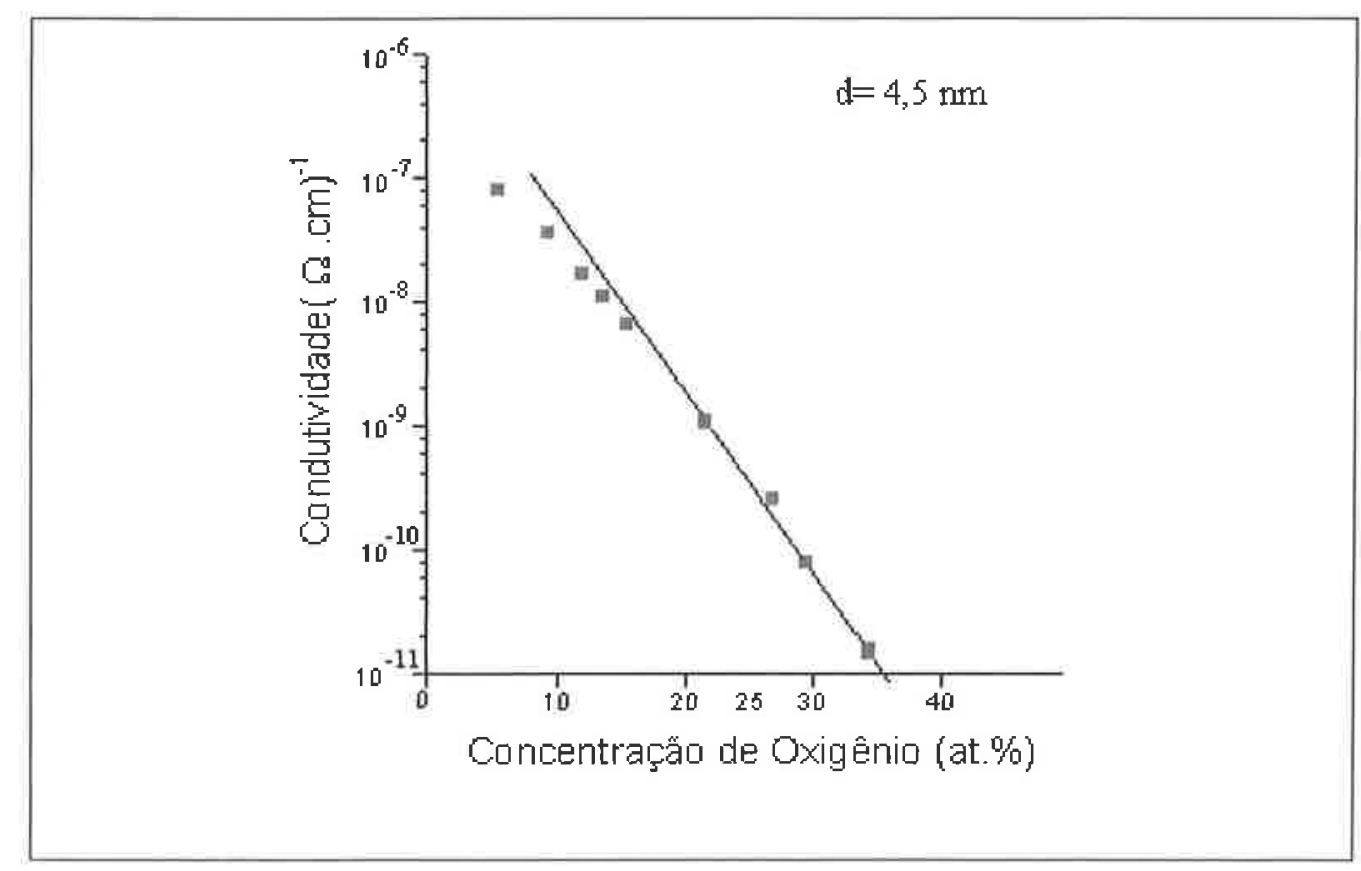

Figura 7. Comportamento experimental da condutividade do filme SIPOS em função da concentração de oxigênio obtida no modelo proposto por Ni e Arnold.

Na figura 7 observamos que com o aumento da concentração de oxigênio presente no filme, temos um redução na condutividade elétrica do filme SIPOS. Com o aumento da concentração de oxigênio presente no filme depositado temos uma maior presença de oxigênio nos contornos de grãos. Desta forma, estamos aumentando a distância entre os grãos de silício, o que implica em um aumento da barreira de potencial entre os grãos; diminuindo-se assim a condutividade elétrica no agregado policristalino. ${ }^{[1,[3]}$

Já na figura 8, apresentamos o comportamento elétrico de uma junção $\mathrm{P} / \mathrm{N}$ quando 
passivada com o filme SIPOS.

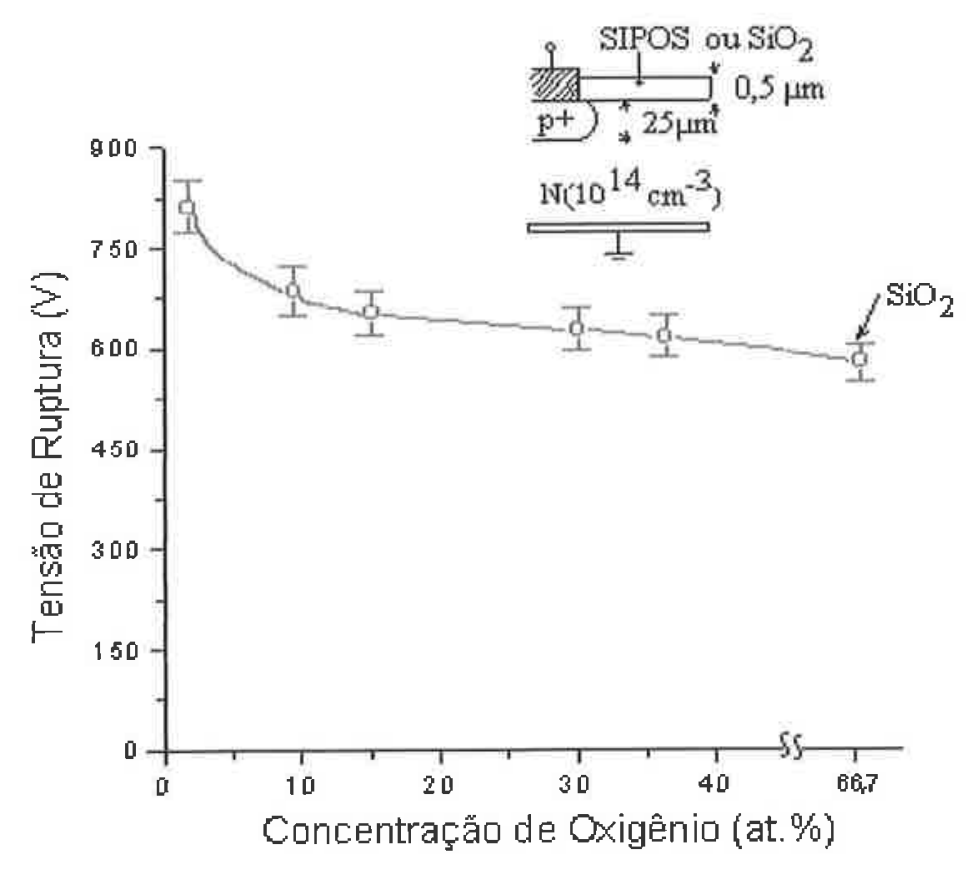

Figura 8. Comportamento experimental da influência da concentração de oxigênio na tensão de ruptura em uma junção $P / N^{[3]}$

Nesta figura, observamos que os maiores valores da tensão de ruptura são obtidos quando temos uma baixa concentração de oxigênio ( 8 átomos \%) presente no filme SLPOS. Entretanto, com o aumento da concentração de oxigênio, observamos que a tensão de ruptura tende a valores próximos aos obtidos com o óxido de silício. Assim sendo, podemos dizer que a diminuição da tensão de ruptura esta relacionada com o aumento de oxigênio no filme. Com o aumento de oxigênio, menor será o relaxamento do campo elétrico superficial; o que diminui a condutividade elétrica no filme. Consequentemente, a tensão de ruptura suportada pela junção $\mathrm{P} / \mathrm{N}$ também será menor. ${ }^{[1],[14]}$

Com base no modelo proposto ${ }^{[28]}$ podemos concluir que o controle da concentração de oxigênio e o tamanho de grão de silício influi diretamente na condutividade elétrica; e por conseguinte na tensão de ruptura da junção $\mathrm{P} / \mathrm{N}$. O controle da concentração de oxigênio no filme SIPOS é feita através do ajuste dos fluxos gasosos entre os gases reagentes. Entretanto, o controle sobre o tamanho de grão é mais complexo, pois é necessário o controle não somente sobre os fluxos gasosos, como sobre os outros parâmetros de processos como a pressão e a temperatura. 


\section{Capítulo 3 .}

\subsection{Fatores que influenciam a produção industrial de dispositivos semicondutores}

\subsection{Introdução}

A produção industrial em microeletrônica envolve o processo de fabricação de um determinado produto em grande escala de produção. Entretanto, sabe-se que em um mesmo lote do mesmo produto, existem certas variações nas características da qualidades do produto que podem influenciar direta ou indiretamente o desempenho do produto final. Para minimizar algumas das variações nas características da qualidade destes produtos, faz-se uso de um controle de qualidade da produção. ${ }^{[32]}$

No próximo item, apresentaremos alguns dos fatores mais comuns que provocam as variações das características da qualidade dos produtos fabricados.

\subsection{Fatores que afetam a qualidade dos dispositivos}

Idealmente, podemos pressupor que todos os dispositivos fabricados de um mesmo lote, a partir de um mesmo processo de fabricação, preserve as mesmas características físicas e elétricas por um determinado intervalo de tempo. Entretanto, na prática o número de dispositivos fabricados com tais características não ultrapassam $50 \%$. Usualmente, as principais causas desta baixa produtividade estão correlacionadas aos seguintes fatores ${ }^{[33]}$ :

a) variação nos equipamentos:

Durante o processo de obtenção de filmes finos de silício policristalino por LPCVD, a variação da espessura nos filmes depositados; decorre da variação dos parâmetros de deposição do equipamento (temperatura, pressão interna do sistema, razão gasosa entre os gases reagentes e espaçamento entre as lâminas).

b) variação no material

A variação encontrada nos materiais pode ser causada por defeitos intrínsecos do próprio material ou serem gerados e/ou incorporados durante o processo de fabricação dos 
dispositivos semicondutores Em dispositivos de pequenas dimensões, tais como transistores MOS, a rugosidade da lâmina de silício exerce uma função degenerativa do dispositivo. Isto porque a irregularidade do substrato pode servir como local suscetível , para defeitos. Por conseguinte, estes defeitos tendem a provocar uma instabilidade elétrica do dispositivo, reduzindo-se assim o seu tempo de vida útil. ${ }^{[33]}$

Um exemplo de defeitos gerados ou incorporados durante a processo de obtenção, acontece durante a deposição de filmes finos em reatores de baixa pressão (LPCVD). No intervalo que precede a inserção das mesmas ao interior do reator, algumas cargas que estejam presentes no ambiente, tais como sódio e potássio podem ser levadas entre as lâminas ou mesmo sobre o carregador. Estas cargas são denominadas cargas móveis e são altamente prejudiciais ao desempenho do dispositivo; pois aumentam a instabilidade elétrica levando à uma redução no seu tempo de vida útil. ${ }^{[14]}$ Outro tipo de carga encontrada em filmes de óxido de silício são as cargas fixas, estas cargas que ficam aprisionadas durante a formação do óxido ou então são provenientes de ligações incompletas entre o silício e o oxigênio originando compostos $\mathrm{Si}-\mathrm{O}$. $\mathrm{Na}$ figura 9, representamos esquematicamente as principais tipos de cargas presentes em filmes de óxido de silício.

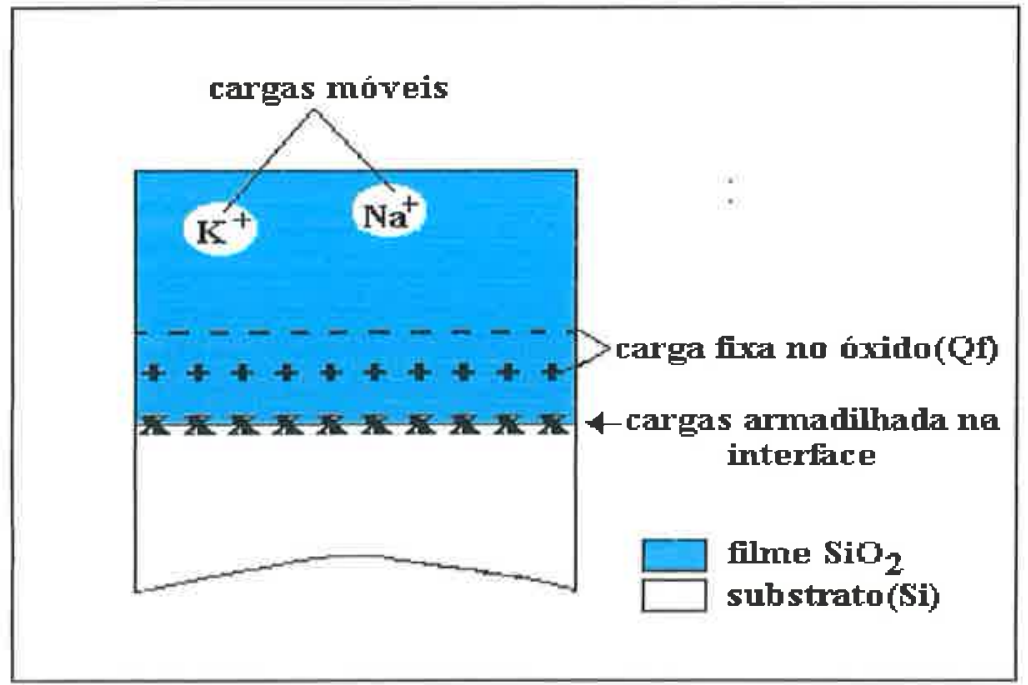

Figura 9. Representação esquemática dos principais tipos de cargas presentes em filmes de oxido de silicio

Além disso, a escolha do tipo de material empregado para a fabricação dos dispositivos semicondutores também exercem influência no desempenho elétrico dos 
mesmos.

Atualmente sabe-se que estes filmes finos, independentemente do meio pelo qual são depositadas, possuem uma tensão mecânica interna que influem no desempenho do dispositivo fabricado. Em geral, as tensões mecânicas em filmes finos são grandes, da ordem de 0,1 a $1 \mathrm{GPa}\left(10^{9}\right.$ a $10^{10}$ dinas $\left./ \mathrm{cm}^{2}\right)$. Uma tensão mecânica desta magnitude aplicado à metais de corpo leva a maior parte destes ao limite elástico. É também suficiente para sobrepor-se a adesão interfacial filme-substrato, se esta adesão é devido somente a adsorção física, podendo causar o descolamento do filme. ${ }^{[34]}$

c) variação nas medições, causada pela não aferição e/ou calibração dos equipamentos utilizados para realização da caracterização física e elétrica dos filmes depositados;

d) variação provocada por erros inerentes decorrentes do processo de fabricação dos dispositivos semicondutores.

Durante o processo de fabricação de dispositivos semicondutores temos em muitas vezes a ocorrência de vários destes efeitos mencionados que afetam diretamente desempenho elétrico, e por conseguinte, o tempo de vida dos dispositivos produzidos. Durante o processo litográfico, caso não ocorra um adequado alinhamento da máscara sobre o dispositivo na subsequente etapa de corrosão de óxido pode ocorrer a remoção do filme em regiões importantes. Isto implicará em um mal funcionamento do dispositivo.

Portanto, podemos concluir que as variações nas características da qualidade dos dispositivos fabricados são resultado da soma destes quatro tipos de fatores descritos anteriormente. Deste modo, é necessário descobrir qual(s) destes fatores contribuem para variação da qualidade da produção e quais variações devem ser controladas e, então delinear formas para controla-las.

No âmbito industrial é comum realizar um controle de qualidade através de repetições de análise e melhoramento, visando atenuar estas variações da qualidade nos produtos fabricados. ${ }^{[32],[33]}$

No controle da qualidade tentamos descobrir as causas destas variações de qualidade e através da coleta de dados, determinamos a ação necessária para amenizar as 
variações encontradas, baseando-se na interpretação dos dados coletados. Os dados não são apenas coletados como um objetivo final em si; mas sim com uma maneira de descobrir os fatos que estão por detrás dos mesmos. ${ }^{[32]}$

Admitimos que a coleta de dados geralmente é feita uma inspeção por amostragem. Em uma amostra de um lote de dispositivos fabricados, por exemplo, executa-se várias medições, e então verifica-se o comportamento elétrico do mesmo para decidirmos sobre o conjunto total do lote. A preocupação principal não é com a amostra em si; mas sim com a qualidade do lote todo .

A totalidade dos itens coletados é chamada de população. No exemplo citado, a população são os dispositivos. Quando um ou mais itens são retirados de uma população com a intenção de prover informações sobre a mesma; chamamos de amostras. Quando uma amostra é utilizada para estimar as características de toda a população, essa deve ser escolhida de tal forma a refletir as características da população; conotamos a designação de amostragem aleatória. E quando, retira-se uma amostra deste tipo de amostragem, utilizase a expressão de amostra aleatória.

Portanto através da análise estatística de dados podemos interpretar os resultados encontrados e com isso chegar à conclusão sobre o processo de fabricação dos dispositivos fabricados.

\subsection{Análise estatística}

Os dados obtidos de uma amostra servem como base para uma decisão sobre a população. Quanto maior o tamanho da amostra, maior o número de informações sobre a população. Entretanto, com um aumento do tamanho da amostra, maior a quantidade de dados, e isso torna difícil compreender a população a partir destes, mesmo quando estão organizados em tabelas. Desta forma, precisamos de um método que nos possibilite conhecer a população num rápido exame. Por meio de uma organização destes dados em um histograma, podemos conhecer a população de uma maneira mais objetiva. ${ }^{[32],[35]}$

\subsubsection{Medidas para a caracterização das distribuições}

\subsubsection{Médias e Desvio Padrão}

O valor da característica medida em uma amostra, extraída de uma população, varia 
e não pode ser conhecido até que ele seja obtido. Uma variável de tal tipo é chamada de variável aleatória. As características de qualidade de produtos fabricados possuem esta natureza.

É muito mais conveniente estudarmos um conjunto de dados, do que tratarmos individualmente. Deste modo, considerando o conjunto de dados como um grupo, determinamos inicialmente o seu centro, para posteriormente estudarmos como eles se concentram ao redor do centro.

Uma medida típica para expressar o centro é a média ou expectância. Para um conjunto de $n$ dados, $x_{1}, x_{2}, \ldots \ldots \ldots \ldots . . . ., x_{n}$, a média destes dados é representada pela seguinte expressão ${ }^{[36]}$ :

$$
x=\frac{1}{n} \sum_{i=1}^{n} x i \quad \text { Equação I, }
$$

onde $n$ : é o número de pontos e $x_{i}$ denota o ponto $i=1,2,3, \ldots ., \mathrm{n}$.

O desvio padrão absoluto, geralmente chamado de MAD, refere-se a diferença de cada ponto e a média em termos absolutos, isto é, omite-se os sinais positivos ou negativos e determinando-se deste modo, uma média resultante. É importante notarmos que se este procedimento não fosse realizado, o desvio padrão seria sempre nulo. A expressão que representa o desvio médio padrão, é $:^{[33]}$

$$
M A D=\frac{\sum_{i=1}^{n}\left|x_{i}-\bar{x}\right|}{n} \quad \text { Equação } 5
$$

onde: $n$ é o número de pontos, $x_{i}$ denota o ponto $i=1,2,3, \ldots .$, n. e $\bar{x}$ é a média do conjunto dos dados.

A variância é a média do quadrado das diferenças entre os dados individuais e a média. Uma grande variância significa uma grande variação nos dados. Logo, a variância é expressa como sendo: 


$$
V=\frac{1}{n-1} \cdot \sum_{i=1}^{n}\left(x_{i}-\bar{x}\right)^{2} \quad \text { Equação } 6
$$

onde: $\mathrm{V}$ : variância, $\mathrm{n}$ representa os $, \mathrm{x}_{1}, \mathrm{x}_{2}, \mathrm{x}_{\mathrm{n}}$ dados; $\bar{x}$ é a média dos dados.

\subsubsection{Dispersão Absoluta e Relativa. Coeficiente de Variação (CV)}

A variação ou dispersão real, determinada a partir do desvio padrão, ou qualquer outra medida de dispersão, é denominada dispersão absoluta. Entretanto, uma variação ou dispersão de $10 \mathrm{~V}$, na medida de uma tensão reversa de $1.000 \mathrm{~V}$, é inteiramente diferente, quanto ao efeito, da mesma variação de $10 \mathrm{~V}$ em uma tensão de $20 \mathrm{~V}$. A medida desse efeito é proporcionada pela dispersão relativa, definida por :

$$
\text { Dispersão absoluta }=\frac{\text { Dispersão relativa }}{\text { média }} \quad \text { Equação } 7
$$

Se a dispersão absoluta é o desvio padrão (s) e a média é a aritmética $\bar{x}$, a dispersão relativa é denominada coeficiente de variação ou de dispersão, dado por :

$$
\begin{aligned}
& C V=\frac{s}{\bar{x}} .100 \%, \text { onde } \\
& \text { Equação8 } \\
& \bar{x}: \text { média }
\end{aligned}
$$

O Coeficiente de Variação (CV) é geralmente expresso em porcentagem. Note-se que o CV independe da unidades utilizadas. Por esta razão, é vantajosa para a comparação de distribuições cujas unidades podem ser diferentes. Uma desvantagem do CV é que este deixa de ser útil quando a média aritmética esta próxima a zero. 


\section{Capítulo 4}

\subsection{Procedimento Experimental}

\subsection{Condições Experimentais}

Para a realização deste trabalho utilizamos dois lotes de lâminas de silício. Um primeiro lote, constituído de lâminas de silício tipo $P$, orientação (100), diâmetro de $75 \mathrm{~mm}$ e resistividade compreendida entre 1 e $10 \Omega$.cm. Um segundo lote, formado por lâminas de silício tipo N (110), diâmetro de $100 \mathrm{~mm}$ e resistividade entre 1 e $15 \Omega . c m$, contendo os diodos de potência semi processados.

$\mathrm{Na}$ figura 10 esquematicamente representamos as etapas de fabricação dos diodos de potência.

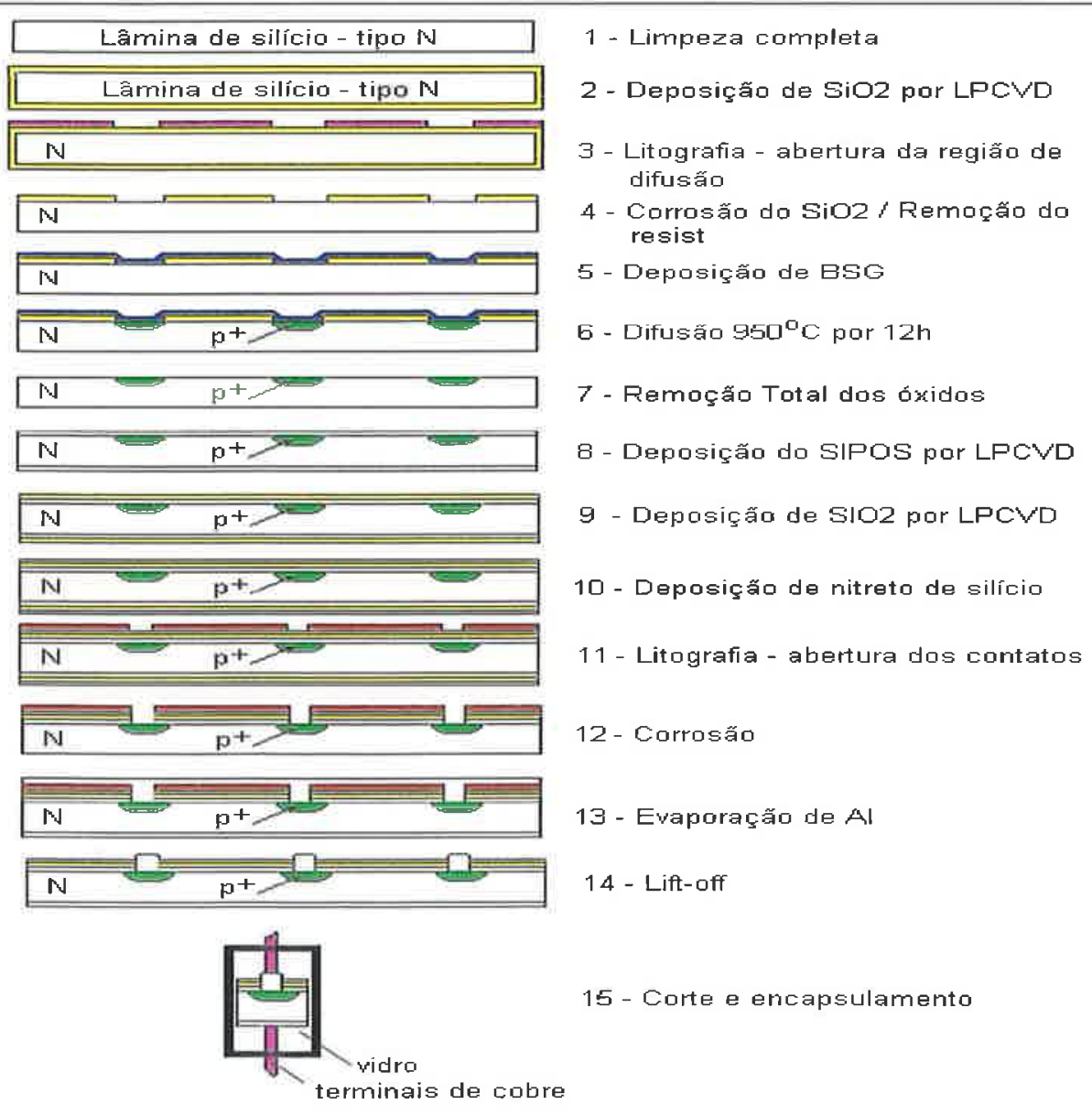

Figura 10. Etapas de processos de um diodo de alta potência 
Os diodos de potência que são utilizados neste trabalho, apresentam uma dimensão de 4,0 mm x 4,0 mm. Na figura 11, representamos uma lâmina semi-processada contendo os diodos de potência.

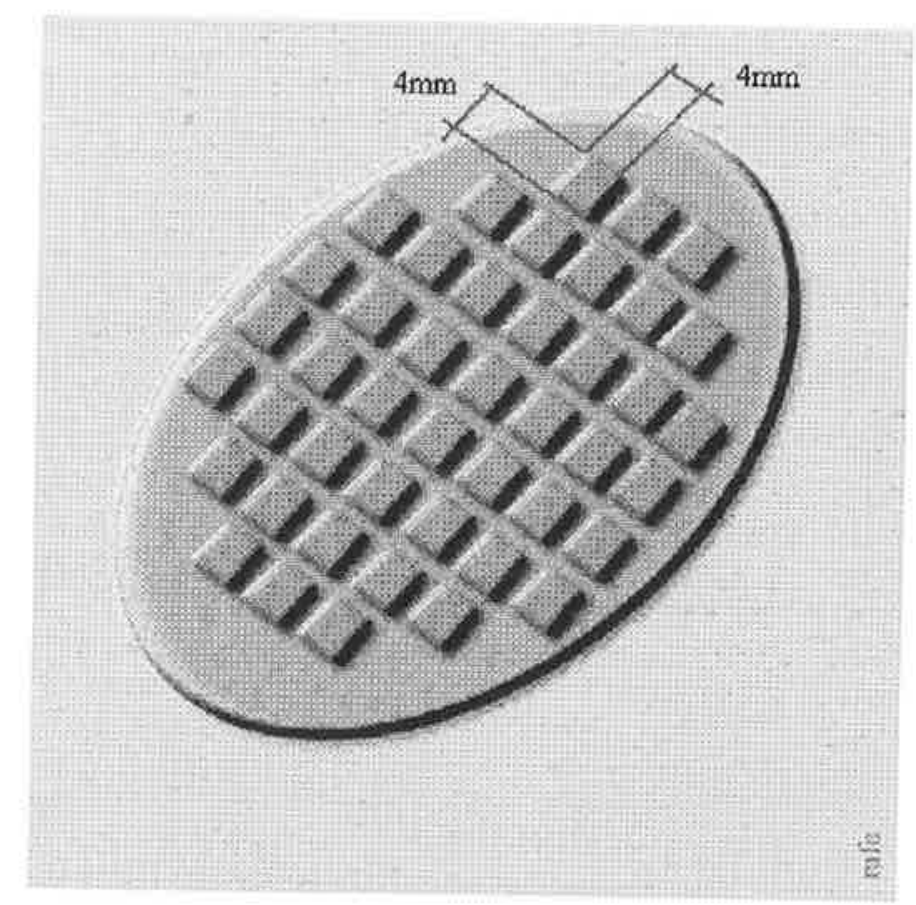

Figura 11. Representação de uma lâmina de silício semi-processada contendo os diodos de potência; fornecida pela Aegis Semicondutores Ltda

Em virtude da dimensão, da orientação cristalográfica e principalmente pela fragilidade das lâminas de silício que continham os diodos de potência; utilizamos um crivador de lâminas modelo D-8016 para dividir estas lâminas em quatro pedaços. Cada um destes pedaços foram utilizados para determinar alguns parâmetros de processo do LPCVD (pressão, razão gasosa, espaçamento e o tempo de processo).

\subsection{Processo de deposição do filme SIPOS por LPCVD} (RCA):

As lâminas de silício, foram submetidas ao seguinte processo de limpeza química

a) Enxágüe com água deionizada, durante 5 minutos;

b) Imersão na solução de 1: $\mathrm{HF}$ : $20 \mathrm{H}_{2} \mathrm{O}$; durante alguns segundos

c) Enxágüe com água deionizada durante 2 minutos; 
d) Imersão na solução de $4 \mathrm{H}_{2} \mathrm{O}: 1 \mathrm{H}_{2} \mathrm{O}_{2}: 1 \mathrm{NH}_{4} \mathrm{OH}$,à $105^{\circ} \mathrm{C}$ durante 10 minutos;

e) Enxágüe com água deionizada durante 5 minutos;

f) Imersão na solução de $4 \mathrm{H}_{2} \mathrm{O}: 1 \mathrm{H}_{2} \mathrm{O}_{2}: 1 \mathrm{HCl}$, à $105^{\circ} \mathrm{C}$ durante 10 minutos;

g) Enxágüe com água deionizada durante 5 minutos;

h) Imersão na solução de 1 : $\mathrm{HF}: 20 \mathrm{H}_{2} \mathrm{O}$ por alguns segundos.

A temperatura de processo do reator LPCVD é ajustada em $700^{\circ} \mathrm{C}$. Para isso, utilizamos o termopar tipo K (Alumel/Cromel), ajustando-se a temperatura sempre da parte central do reator para as suas extremidades. Este procedimento é comumente utilizado para se garantir a obtenção de um perfil de temperatura de processo constante ao longo do reator, ou seja, para a obtenção de uma planaridade quanto ao perfil térmico.

Antes de depositarmos o filme SIPOS, crescemos uma camada de óxido de silício utilizando um fluxo de óxido nitroso; a qual denominamos de camada de pré-oxidação. $\mathrm{O}$ fluxo do óxido nitroso utilizado durante a formação da camada de pré-oxidação é o mesmo utilizado durante o processo de deposição do filme SIPOS.

Em seguida, realizamos o processo de deposição do filme SIPOS por LPCVD.

A figura 12 mostra o carregador de quartzo utilizado para a deposição do filme SIPOS bem como a distribuição das lâminas no seu interior.

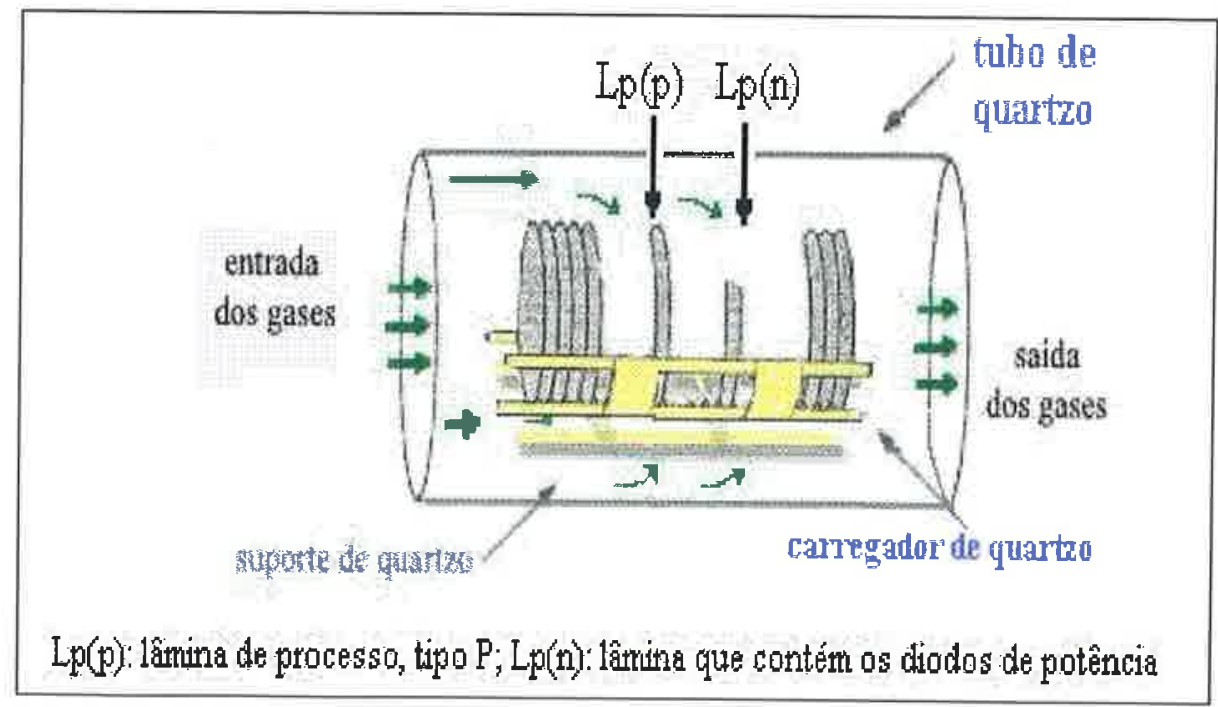

Figura 12. Carregador de quartzo utilizado para a deposição do filme SIPOS bem como a distribuição das lâminas no seu interior. 
$\mathrm{Na}$ figura 12, representamos as duas lâminas de processo pelas siglas $\mathrm{Lp}(\mathrm{p})$ e $\mathrm{Lp}(\mathrm{n})$. A sigla $\mathrm{Lp}(\mathrm{p})$, refere-se à uma lâmina de silício do tipo $\mathrm{P}$ e a sigla $\mathrm{Lp}(\mathrm{n})$ refere-se à uma lâmina tipo $\mathrm{N}$, que continham os diodos de potência semi-processados, fornecidos pela Aegis Semicondutores Ltda. As demais lâminas presentes sobre o carregador tinham como principal finalidade, uniformizar o fluxo da mistura gasosa $\left(\mathrm{N}_{2} \mathrm{O} / \mathrm{SiH}_{4}\right)$ sobre estas lâminas, o que garante uma boa uniformidade em espessura dos filmes depositados.

Ainda nesta figura utilizamos também um suporte de quartzo sobre o carregador. Este suporte tem como finalidade centralizar o carregador no tubo de quartzo, uniformizando a passagem da mistura gasosa $\left(\mathrm{N}_{2} \mathrm{O} / \mathrm{SiH}_{4}\right)$, que por sua vez contribui para melhorar a uniformidade em espessura do filme depositado.

\subsection{Filmes SIPOS depositados}

Na tabela 2, apresentamos os experimentos realizados para a determinação da melhor condição de processo de deposição do filme SIPOS por LPCVD.

Tabela 2. Condições Experimentais utilizadas em nosso trabalho. A temperatura de processo e ofluxo de silana foram mantidas constantes em $700^{\circ} \mathrm{C}$ e em $30 \mathrm{sccm}$,

\begin{tabular}{|c|c|c|c|c|c|c|}
\hline Amostras & $\begin{array}{c}\text { Pressão } \\
\text { (Torr) }\end{array}$ & $\begin{array}{c}\text { Razão } \\
\text { gasosa } \\
\left(\mathrm{N}_{2} \mathrm{O} / \mathrm{SiH}_{4}\right)\end{array}$ & $\begin{array}{c}\text { Fluxo } \\
\text { de } \mathrm{N}_{2} \mathrm{O} \\
(\mathrm{sccm})\end{array}$ & $\begin{array}{c}\text { Tempo } \\
\text { da } \\
\text { pré- } \\
\text { oxidação } \\
(\mathrm{s})\end{array}$ & $\begin{array}{c}\text { Espaçamento } \\
\text { entre as } \\
\text { lâminas (mm) }\end{array}$ & $\begin{array}{c}\text { Tempo } \\
\text { de } \\
\text { Processo } \\
(\mathrm{min})\end{array}$ \\
\hline MFA1.1 & 0,20 & 0,30 & 9 & 60 & 15 & 10 \\
\hline MFA1.2 & 0,20 & 0,57 & 17 & 60 & 15 & 12 \\
\hline MFA1.3 & 0,20 & 0,83 & 25 & 60 & 15 & 14 \\
\hline MFA2.1 & 0,30 & 0,30 & 9 & 60 & 15 & 6 \\
\hline MFA2.2 & 0,30 & 0,57 & 17 & 60 & 15 & 8 \\
\hline MFA2.3 & 0,30 & 0,83 & 25 & 60 & 15 & 10 \\
\hline MFA3.1 & 0,20 & 0,30 & 9 & 60 & 20 & 10 \\
\hline MFA3.2 & 0,20 & 0,30 & 9 & 60 & 25 & 10 \\
\hline MFA3.3 & 0,20 & 0,30 & 9 & 60 & 30 & 10 \\
\hline MFA4.1 & 0,20 & 0,30 & 10 & 42 & 20 & 10 \\
\hline MFA5.1 & 0,20 & 0,30 & 10 & 24 & 20 & 10 \\
\hline
\end{tabular}


A proporção gasosa $\left(\mathrm{N}_{2} \mathrm{O} / \mathrm{SiH}_{4}\right)$ variou entre 0,30 e 0,83 . As pressões de processo utilizadas em nossos experimentos foram de 0,20 e 0,30 Torr. Com relação ao espaçamento deixado entre as lâminas de processo, partimos inicialmente de um espaçamento de 15 $\mathrm{mm}$.

A literatura relata que em se tratando dos dispositivos de potência é importante a realização de uma etapa de densificação das amostras depositadas com o filme SIPOS; geralmente à uma temperatura de $900^{\circ} \mathrm{C}$ em ambiente de nitrogênio, pois o filme SIPOS é

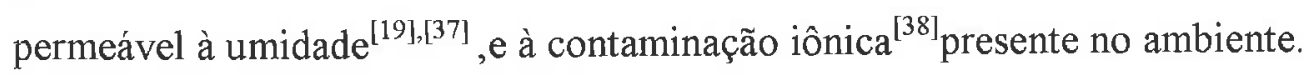

Com base nisto, realizamos uma etapa de densificação de nossas amostras representadas na tabela 2 pela amostra MFA4.1 com nitrogênio à $900^{\circ} \mathrm{C}$ durante 15 minutos.

A etapa de pré-oxidação, para a formação de uma fina camada de óxido de silício, tem por finalidade previnir a formação de uma camada rica em silício junto à interface silício-SIPOS ${ }^{[13]}$, reduzindo a corrente de fuga superficial. Sandoe ${ }^{[26]}$ verificou experimentalmente que sem esta camada de pré-oxidação, o relaxamento da região de depleção será limitada apenas pela corrente que flui através da interface SIPOS-Si. Deste modo, o campo elétrico superficial próximo à interface SIPOS-Si aumenta, o que provoca uma redução da tensão de ruptura na junção semicondutora.

Na caracterização elétrica dos diodos, observamos uma instabilidade elétrica que foi associada à umidade presente no ambiente. Assim, estes diodos foram submetidos a um tratamento térmico a $120^{\circ} \mathrm{C}$ durante 15 minutos em uma estufa.

\subsection{Técnicas de caracterização e equipamentos utilizados neste trabalho}

Para a caracterização de nossas amostras depositadas com o filme SIPOS utilizamos as seguintes técnicas:

a) Espectroscopia de Infravermelho por transformada de Fourier (FTIRS): para a determinação das ligações químicas ( $\mathrm{Si}-\mathrm{O}, \mathrm{Si}-\mathrm{O}-\mathrm{Si}$, Si-H e Si-OH) presentes nos filmes depositados; 
b) Espectrometria de Retroespalhamento Rutherford (RBS): para a determinação da concentração de oxigênio presente em nossas amostras depositadas. (ver anexo 2);

c) Elipsometria, para determinar a taxa de deposição dos filmes depositados. A taxa de deposição do filme SIPOS foi obtida a partir da espessura média de 25 posições equidistantes da lâmina de silício processada. Para isto, utilizamos dois comprimentos de ondas diferentes $(628,3 \mathrm{~nm}$ e $830,0 \mathrm{~nm})$ em cada posição da lâmina; o que nos garantiu uma maior precisão nos resultados.

d) Capacitores MSS (Metal-SIPOS-Silício) ${ }^{[39]}$ foram utilizadas para a determinação da condutividade do filme SIPOS.

A figura 13 mostra os capacitores fabricados que possuem uma dimensão de $700 \mu \mathrm{m}$ $\mathrm{x} 700 \mu \mathrm{m}$.

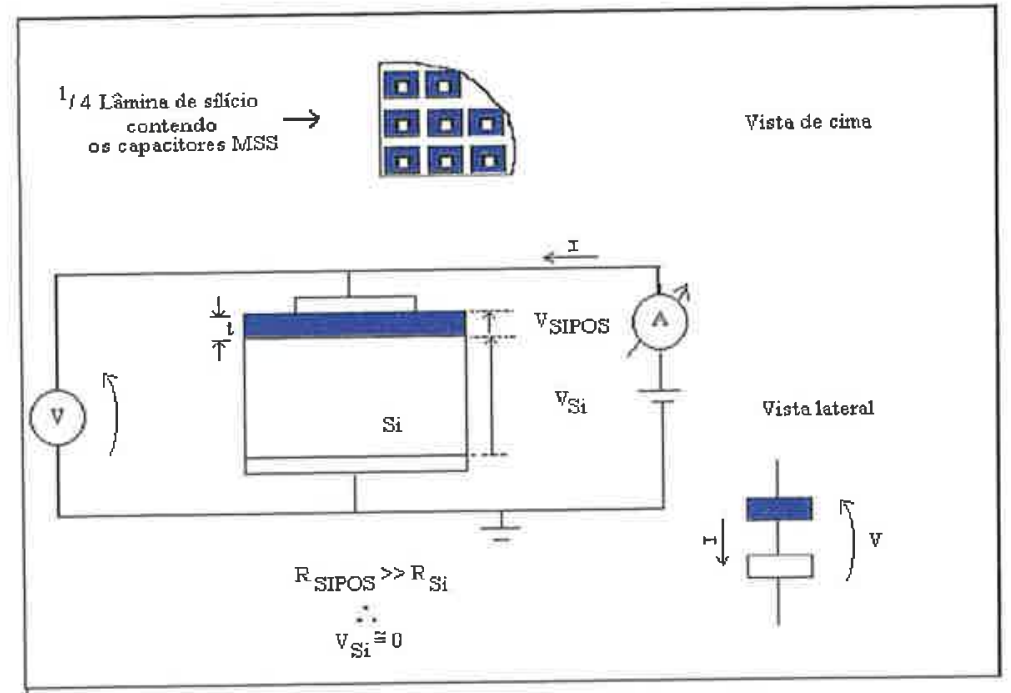

Figura 13. Capacitores MSS fabricados com ofilme SIPOS

Para a determinação a condutividade do filme depositado, aplicou-se um potencial sobre os capacitores MSS fabricados e através da curva IxV extraiu-se diretamente o valor da corrente para determinar a resistência do filme.

Conhecendo-se previamente a espessura do filme, a área dos capacitores bem como a resistência do filme determinou-se a resistividade do filme SIPOS, através da equação 8 além de seu inverso a condutividade (equação 9) . 


$$
R=\rho_{\text {SIPOS }} \cdot \frac{A}{t}
$$

Equação 7

$$
\rho_{\text {SIPOS }}=R \cdot \frac{t}{A}
$$

$$
\sigma=\frac{1}{\rho}
$$

Equação 8

onde R: resistência do filme, A: área do capacitor ,

$\mathrm{t}$ : a espessura do filme SIPOS.

$\rho$ : a resistividade $\mathrm{e}$

$\sigma:$ a condutividade do filme SIPOS.

e) Traçador de Curva Reversa (IxV), para determinarmos a tensão de ruptura dos diodos de potência e a sua corrente reversa.

f) Estufa MEMMERT, modelo 200 para removermos a umidade da superficie dos diodos de potência. 


\section{Capítulo 5-}

\subsection{Resultados e discussões}

\subsubsection{Taxa de deposição do filme SIPOS}

Inicialmente, estudamos o comportamento da taxa de deposição do filme SIPOS em função da proporção gasosa entre os gases reagentes $\left(\mathrm{N}_{2} \mathrm{O} / \mathrm{SiH}_{4}\right)$, nas diferentes pressões de processo; figura 14.

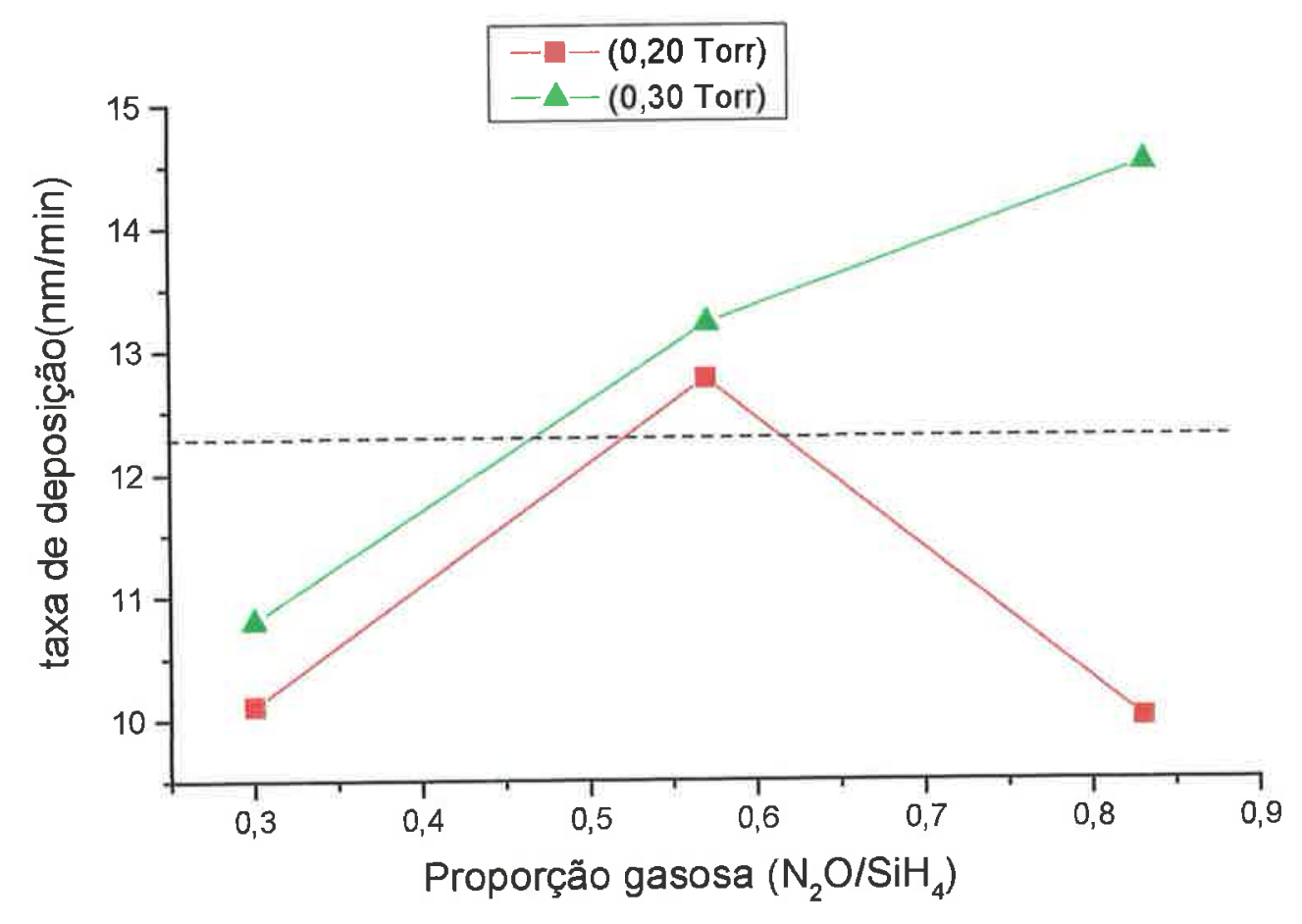

Figura 14. Taxa de deposição do filme SIPOS em função da proporção gasosa $\left(\mathrm{N}_{2} \mathrm{O} / \mathrm{SiH}_{4}\right)$. A linha tracejada refere-se a taxa de deposição média obtida em outros trabalhos. ${ }^{[19]}$

Podemos observar na figura 14 , que a taxa de deposição média do filme SIPOS depositado foi de aproximadamente $12,8 \mathrm{~nm} / \mathrm{min}$. Este resultado esta de acordo com a literatura. ${ }^{[19]}$ 
A taxa de deposição do filme SIPOS é maior quando utilizamos pressões maiores, pois há um aumento da concentração de reagentes. Verificamos ainda que ocorre uma diminuição da taxa de deposição do filme quando utilizamos uma pressão de 0,20 Torr e uma proporção gasosa $\left(\mathrm{N}_{2} \mathrm{O} / \mathrm{SiH}_{4}\right)$ acima de 0,53 . Podemos atribuir esta diminuição ao aumento do fluxo de óxido nitroso que diminui a pressão parcial de silana e aumenta a concentração de $\mathrm{H}_{2} \mathrm{SiO}$ para a subsequente formação de $\mathrm{SiO}$ com uma taxa menor. Isto implica em uma redução na taxa de deposição do filme SIPOS.

Entretanto, não observamos esta diminuição da taxa de deposição do filme SIPOS quando aumentamos a pressão para 0,30 Torr. Isto indica que em proporções gasosas 1:1, ou seja, inserindo-se aproximadamente os mesmos fluxos gasosos torna-se necessário aumentar a pressão de processo para favorecer um aumento da taxa de deposição dos filmes depositados.

\subsubsection{A influência do espaçamento entre as lâminas na uniformidade em espessura e na concentração de oxigênio presente no filme SIPOS}

A figura 15 apresenta o comportamento do espaçamento (S) em função da uniformidade em espessura das amostras depositadas com o filme SIPOS 


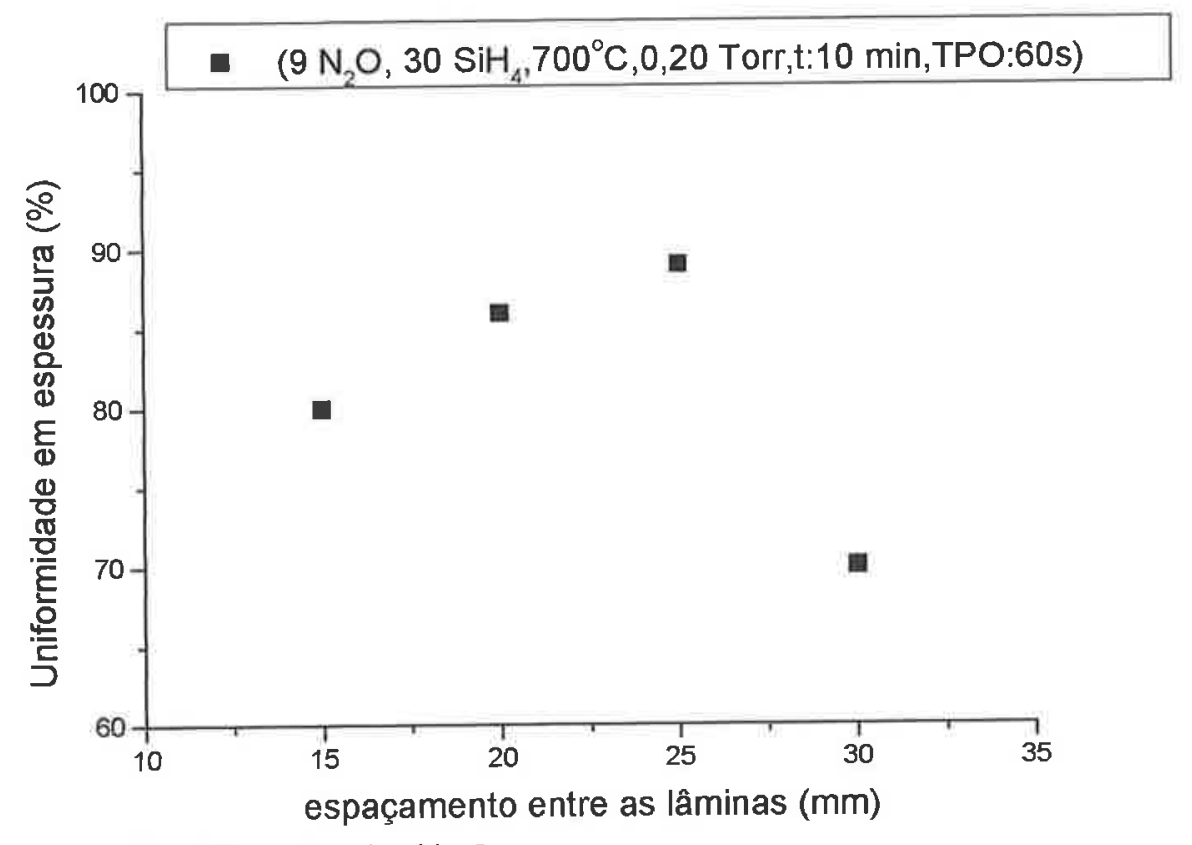

TPO: Tempo de pré-oxidaçāo

Figura 15. O efeito provocado pelo espaçamento entre as lâminas na uniformidade em espessura no filme SIPOS.

$\mathrm{Na}$ figura 15 observamos que com o aumento do espaçamento entre as lâminas de processo, obtivemos uma maior uniformidade em espessura do filme depositado. Este comportamento é atribuído a uma maior uniformidade (regime laminar) do fluxo gasoso dos reagentes na região entre as lâminas. Quando o espaçamento aumenta em demasia (espaçamento maiores do que $25 \mathrm{~mm}$ para este processo) o fluxo gasoso se torna turbulento prejudicando a uniformidade da camada depositada.

Na figura 16 apresentamos os espectros RBS das amostras depositadas com o filme SIPOS, na qual variamos o espaçamento entre as lâminas de processo. Foi utilizado um feixe de Hélio $\left(\mathrm{He}^{+}\right)$, uma energia de incidência de $1,2 \mathrm{MeV}$ e com um ângulo de inclinação da amostra de $60^{\circ}$. 


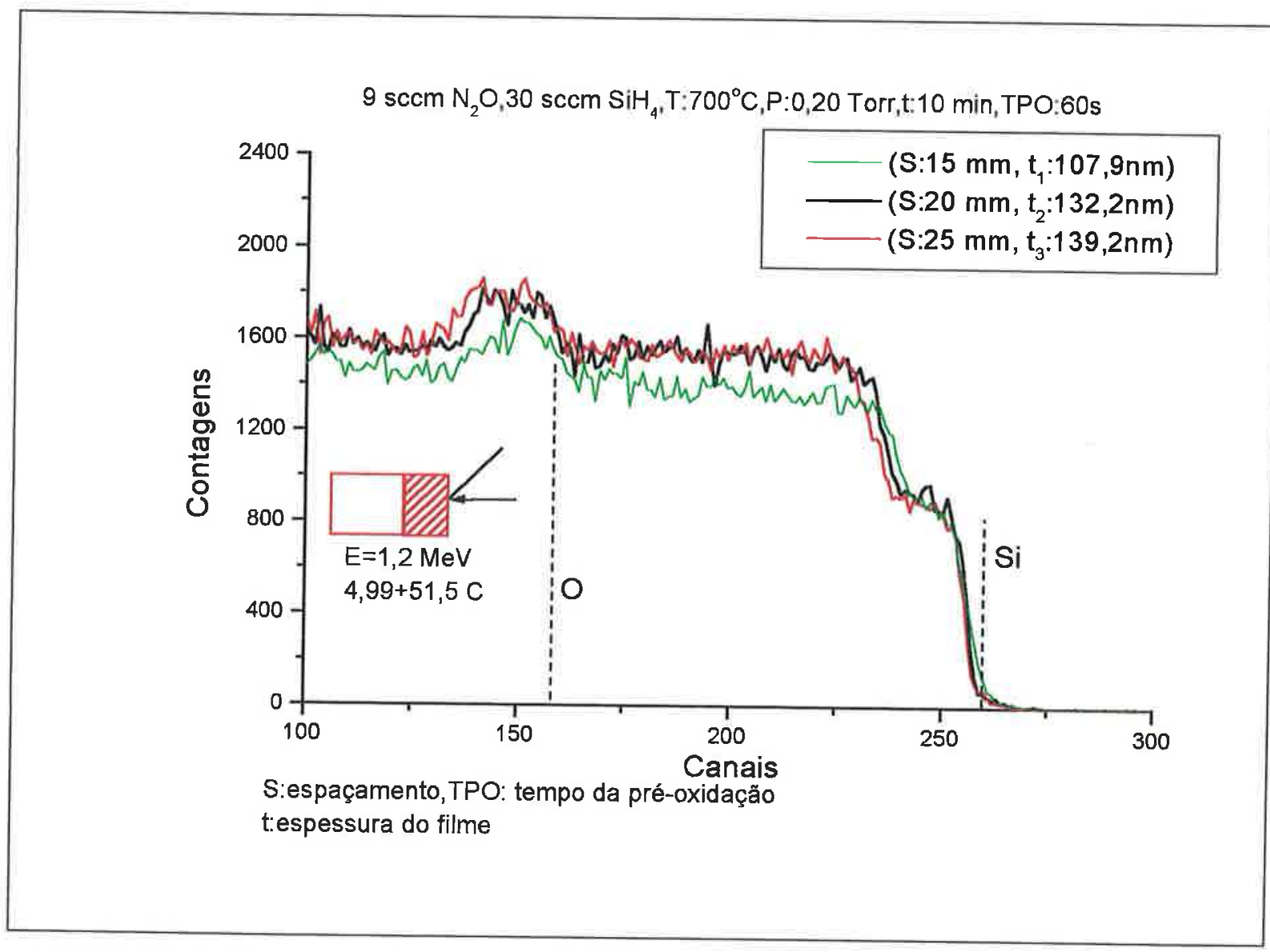

Figura 16. $O$ Espectro RBS das amostras depositadas com diferentes espaçamentos entre as lâminas de processo.

Observamos que em relação à posição do pico de oxigênio, percebemos a existência de dois patamares característicos. Para espaçamento de $(\mathrm{S}=15 \mathrm{~mm})$ temos a formação de um patamar com um formato triangular. Isto indica que a concentração de oxigênio não esta distribuída uniformemente no filme depositado. Entretanto, utilizando-se espaçamentos maiores ( $\mathrm{S}>20 \mathrm{~mm}$ ), o perfil deste patamar apresenta-se com uma maior regularidade quanto concentração de oxigênio presente nos filmes. Pelas figuras 15 e 16 podemos verificar que utilizando-se espaçamentos entre $20 \mathrm{~mm}$ e $25 \mathrm{~mm}$, os filmes depositados apresentaram melhor uniformidade em espessura e em relação a concentração de oxigênio.

A figura 17 mostra a influência da proporção gasosa $\left(\mathrm{N}_{2} \mathrm{O} / \mathrm{SiH}_{4}\right)$ na concentração de oxigênio nos filme SIPOS depositados. 


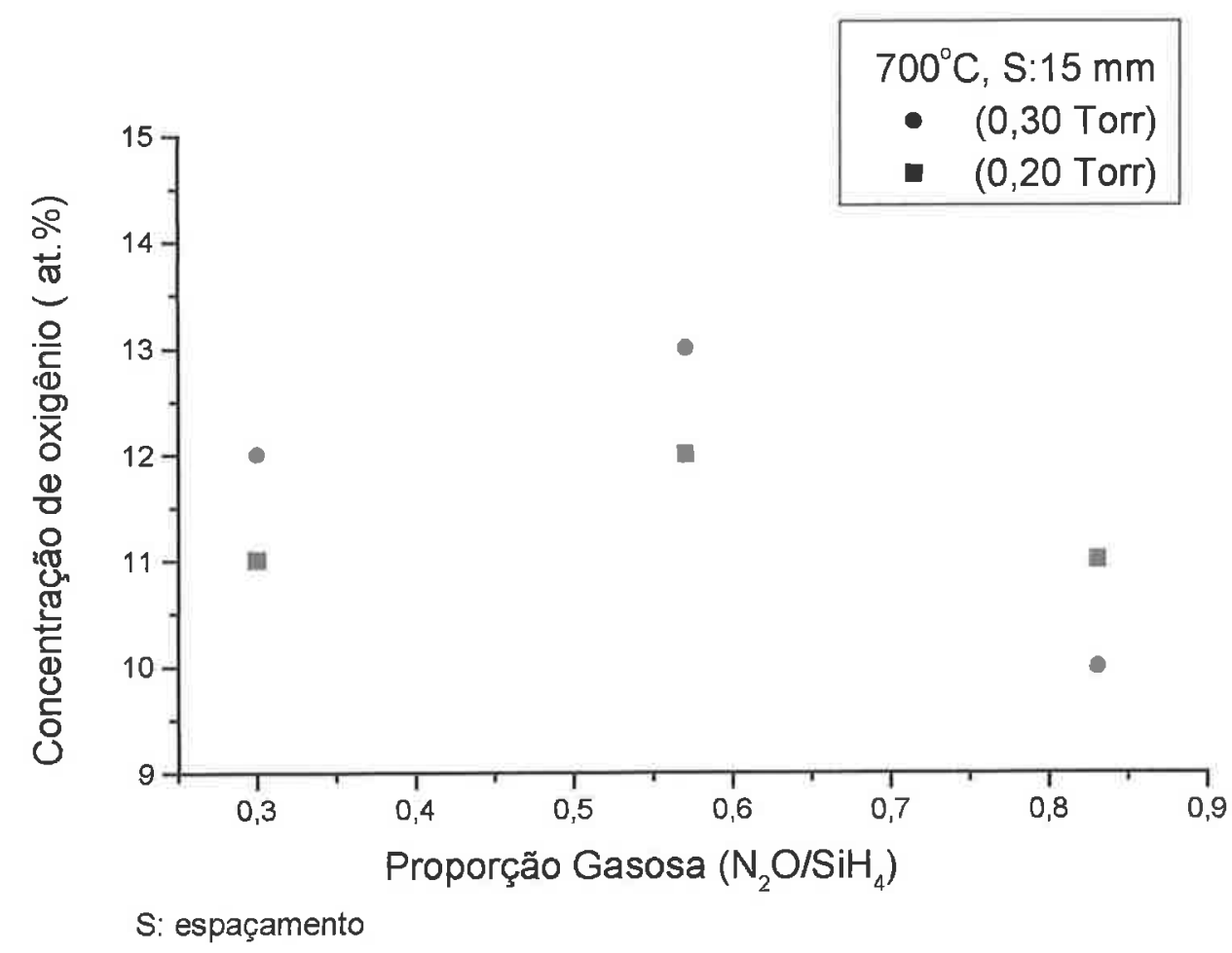

Figura 17. $\mathrm{A}$ influência da proporção gasosa $\left(\mathrm{N}_{2} \mathrm{O} / \mathrm{SiH}_{4}\right)$ na concentração de oxigênio presente nos filmes SIPOS depositados.

O comportamento observado na figura 17 é similar ao encontrado na figura 14. Com o aumento da pressão de processo e utilizando-se razões entre $\left(\mathrm{N}_{2} \mathrm{O} / \mathrm{SiH}_{4}\right)$ inferiores a 0,57, temos uma maior concentração de oxigênio presente no filme SIPOS. Esta diminuição foi observado por B. Verstengen ${ }^{[40]}$ e esta de acordo com a teoria apresentada no item 2.4 .

Através da figura 18 verificamos a influência da proporção gasosa na condutividade elétrica no filme SIPOS, nas duas pressões de processo. 


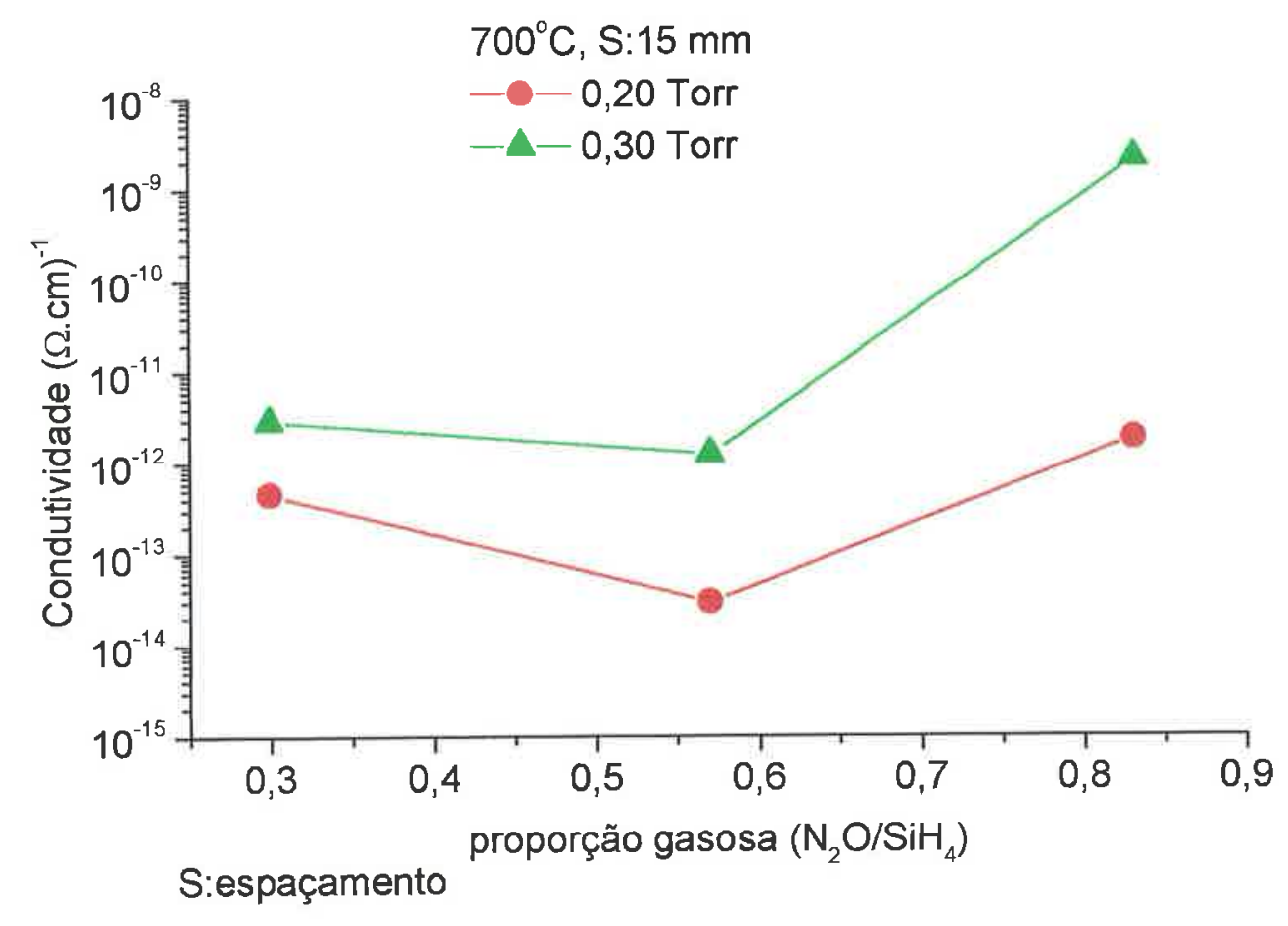

Figura 18. A influência da proporção gasosa na condutividade elétrica nos filmes depositados nas duas pressões de processos.

Como podemos observar na figura 18, independentemente da pressão de processo, com o aumento da proporção gasosa temos a tendência de obter uma menor condutividade elétrica no filme SIPOS. Este comportamento esta coerente com a teoria apresentada no item 2.5. Isto decorre do fato de que com o aumento da proporção gasosa, temos a formação de uma camada de óxido presente ao redor dos grãos de silício, o que causará um aumento da barreira do potencial e por consequência teremos a diminuição da condutividade do filme depositado. ${ }^{[1],[3],[28]}$

\subsubsection{O comportamento elétrico dos diodos de potência após a etapa de densificação do filme SIPOS}

Foi realizado uma etapa de densificação do filme SIPOS em ambiente de nitrogênio à $900^{\circ} \mathrm{C}$ durante 15 minutos. Após a etapa de densificação, caracterizamos eletricamente os diodos de potência na qual verificamos uma degradação do desempenho elétrico dos 
mesmos. Os diodos apresentaram tensões reversa menores que $100 \mathrm{~V}$ além de correntes reversa elevadas. Já os dispositivos que não foram submetidos ao processo de densifícação suportaram uma tensão de ruptura acima de $800 \mathrm{~V}$ e corrente reversa na ordem de alguns miliampéres.

Para compreendermos o motivo desta redução de desempenho elétrico dos diodos de potência, verificamos o comportamento das ligações químicas presentes nas amostras depositadas com o filme SIPOS. Estas ligações químicas foram determinadas por espectroscopia de infravermelho por transformada de Fourier (FTIRS).

$\mathrm{Na}$ figura 19 comparamos os espectros FTIRS antes e após de realizarmos o processo de densificação das amostras depositadas com o filme SIPOS .

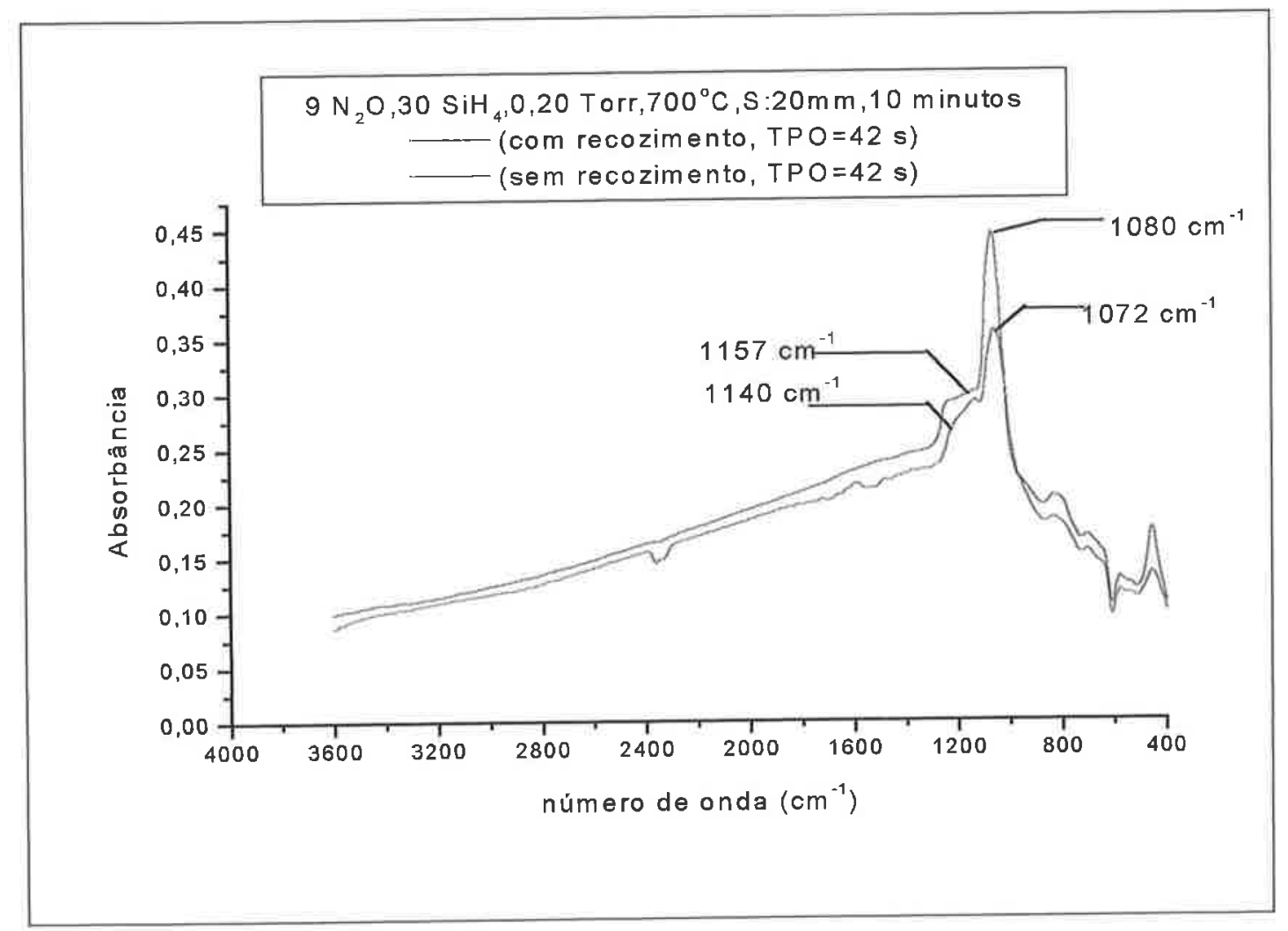

Figura 19. Espectro FTIRS antes e após o processo de densificação das amostras com o filme SIPOS.

$\mathrm{Na}$ figura 19 podemos observar claramente um deslocamento do pico localizado em $1072 \mathrm{~cm}^{-1}$ (antes da densificação) (Si-O-Si) para $1080 \mathrm{~cm}^{-1}$ (após a densificação). Além disso, também observamos um achatamento do joelho encontrado em $1140 \mathrm{~cm}^{-1}$ (antes) quando comparado ao obtido (após a densificação) em $1157 \mathrm{~cm}^{-1}$. Estas mudanças 
mostram que as amostras submetidas ao processo de densificação sofreram mudanças de suas propriedades físicas; o que ocasionou em uma degradação no desempenho elétrico nos dispositivos de potência.

Ferreira $^{41}$, em seu trabalho, através das medidas obtidas por FTIRS e XRD chegou a conclusão de que os filmes SIPOS são constituídos de pequenos grãos de silício, e que o oxigênio segregou para os contornos de grão formando ligações Si-O. Contudo não afirmou se o óxido de silício está formando uma grande região amorfa ou se simplesmente está disperso entre os grãos de silício amorfo. Entretanto pelas intensidades dos picos de $\mathrm{SiO}_{2}$ apresentadas pelas amostras acredita-se que a segunda possibilidade é mais coerente. Desta forma, admitiu-se que existe uma tendência do oxigênio se concentrar nos contornos de grão. Além disso, foi observado a formação de uma fase de $\mathrm{SiO}_{2}$, como é descrito no modelo proposto por Ni e Arnold. ${ }^{[28]}$ 


\subsubsection{Caracterização elétrica dos dispositivos de potência}

Inicialmente, estudamos a influência dos parâmetros do processo de deposição do filme SIPOS (pressão, a razão gasosa entre os gases reagentes $\left(\mathrm{N}_{2} \mathrm{O} / \mathrm{SiH}_{4}\right)$ e o tempo de processo) no desempenho elétrico dos diodos de potência. A meta inicial deste trabalho era de encontrar uma condição de processo de deposição do filme SIPOS que nos propiciasse obter dispositivos de potência que suportassem tensões de rupturas superiores a $800 \mathrm{~V} \mathrm{e}$ com corrente reversas relativamente baixa.

$\mathrm{Na}$ figura 20 apresentamos os histogramas das medidas de tensão de ruptura dos diodos de potência passivados com o filme SIPOS.

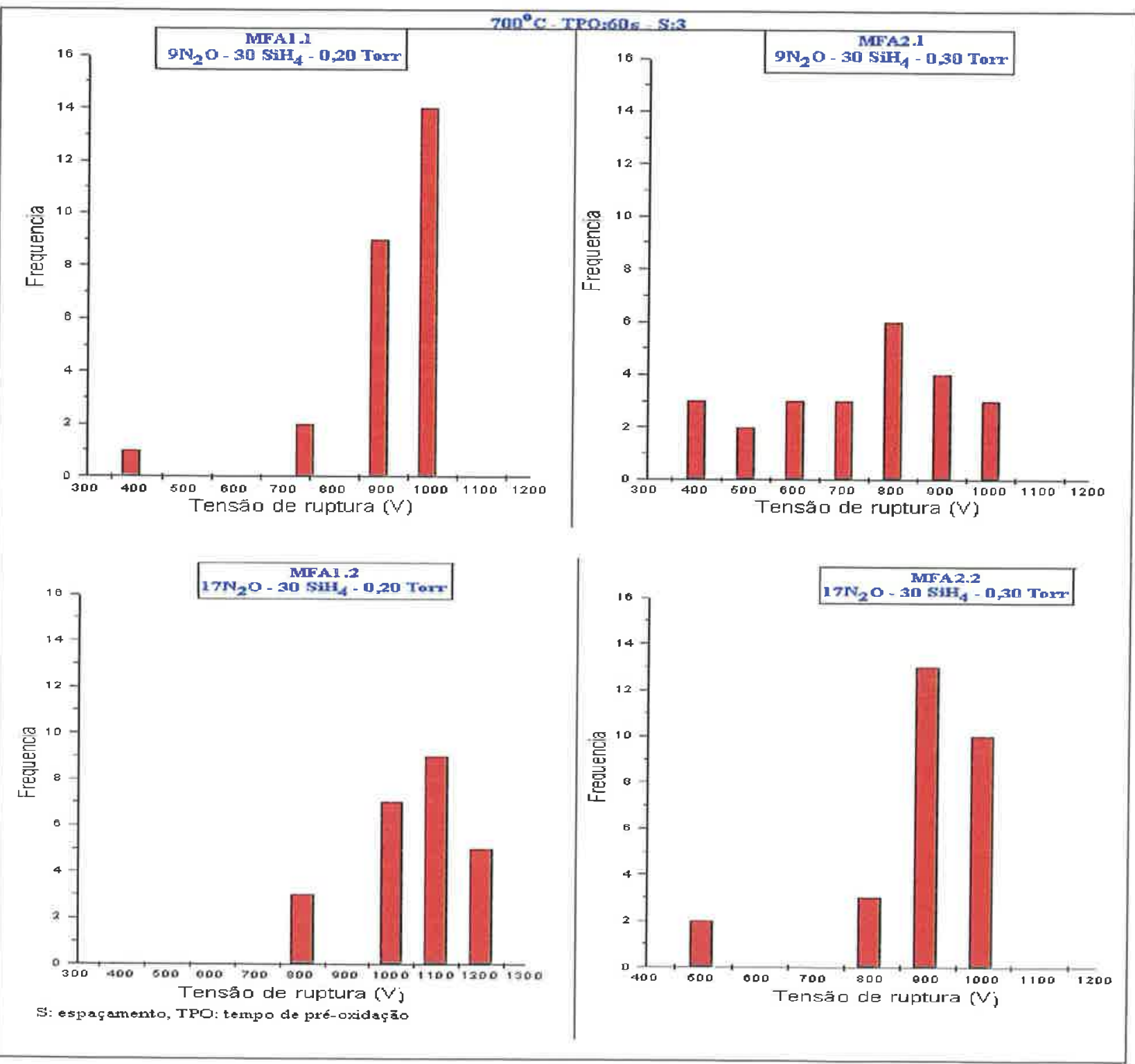

Figura 20. Histogramas dos processos de passivação dos diodos de potência com o filme SIPOS. 
No histograma MFA1.1 observamos uma alta frequência de dispositivos que suportaram tensões superiores a $800 \mathrm{~V}$. Os valores médios encontrados nesta condição foram: tensão de ruptura de $762 \mathrm{~V}$ e corrente reversa de $2,56 \pm 0,18 \mathrm{~mA}$. No histograma MFA1.2, a frequência de dispositivos que suportaram tensões acima de $800 \mathrm{~V}$ foi menor. Os valores médios encontrados nesta condição foram: tensão de ruptura de $700 \mathrm{~V}$ e corrente reversa de 3,14 $\pm 0,45 \mathrm{~mA}$. Já no histograma representado pela sigla MFA2.1, podemos observar uma alta frequência de dispositivos que suportaram tensões reversas acima de $1.000 \mathrm{~V}$. Os valores médios encontrados nesta condição de processo foram: tensão de ruptura de $1.025 \mathrm{~V}$ e corrente reversa de $3,57 \pm 0,23 \mathrm{~mA}$. No histograma MFA2.2, observamos uma diminuição tanto da frequência de dispositivos como também da tensão de ruptura média para $800 \mathrm{~V}$. Além disso, verificamos um aumento da corrente reversa média para $4,39 \pm 0,30 \mathrm{~mA}$

Nos histogramas da figura 20 podemos observar que a pressão de processo e a razão gasosa influem no desempenho elétrico dos diodos de potência. Com o aumento destes parâmetros de processos temos uma diminuição significativa da tensão de ruptura e um aumento da corrente reversa nos dispositivos de potência. Uma explicação para a diminuição no desempenho elétrico esta associado principalmente ao aumento da concentração de oxigênio, que por sua vez diminui a condutividade elétrica nos filmes. Isto implica em uma diminuição da tensão de ruptura nestes dispositivos. Estes resultados foram observados em outros trabalhos. ${ }^{[14],[19]}$

Portanto podemos verificar que o melhor processo de passivação dos diodos de potência com o filme SIPOS foi o encontrado no histograma representado pela sigla MFA1.1. Neste histograma, obtivemos uma alta frequência de dispositivos que suportaram tensões de rupturas superiores a $800 \mathrm{~V}$ e com as menores correntes reversas. Nesta amostra utilizamos a temperatura de $700^{\circ} \mathrm{C}$, pressão de 0,20 Torr, proporção gasosa $\mathrm{N}_{2} \mathrm{O} / \mathrm{SiH}_{4}$ de 0.30 , tempo de pré-oxidação de 60 s e tempo de processo de 10 minutos.

Apesar dos altos valores médios quanto às tensões de ruptura encontrados nos histogramas apresentados, a corrente reversa encontrada nos diodos foi elevada. Como relatamos em outros itens, uma alta corrente reversa diminui o tempo de vida útil nos dispositivos de potência. Assim sendo, procuramos diminuir a intensidade da corrente 
reversa nos diodos de potência a partir da adequação dos parâmetros de deposição do LPCVD (espaçamento entre as lâminas de processo e o tempo para a formação da camada de pré-oxidação).Os demais parâmetros foram mantidos fixos, ou seja, a pressão em 0,20 Torr, proporção gasosa de 0,30 e tempo de processo em 10 minutos.

Experimentalmente, observamos que alguns diodos de potência romperam quando polarizados com tensões reversas superiores a $1.000 \mathrm{~V}$. Isto ficou evidenciado por pontos brancos na região próximo as bordas dos dispositivos. Este comportamento se deve ao elevado campo elétrico nestas regiões; assim como descrito no item 1.1. ${ }^{[1],[4]}$

$\mathrm{Na}$ figura 21 relacionamos a influência do espaçamento entre as lâminas no comportamento elétrico dos diodos de potência.

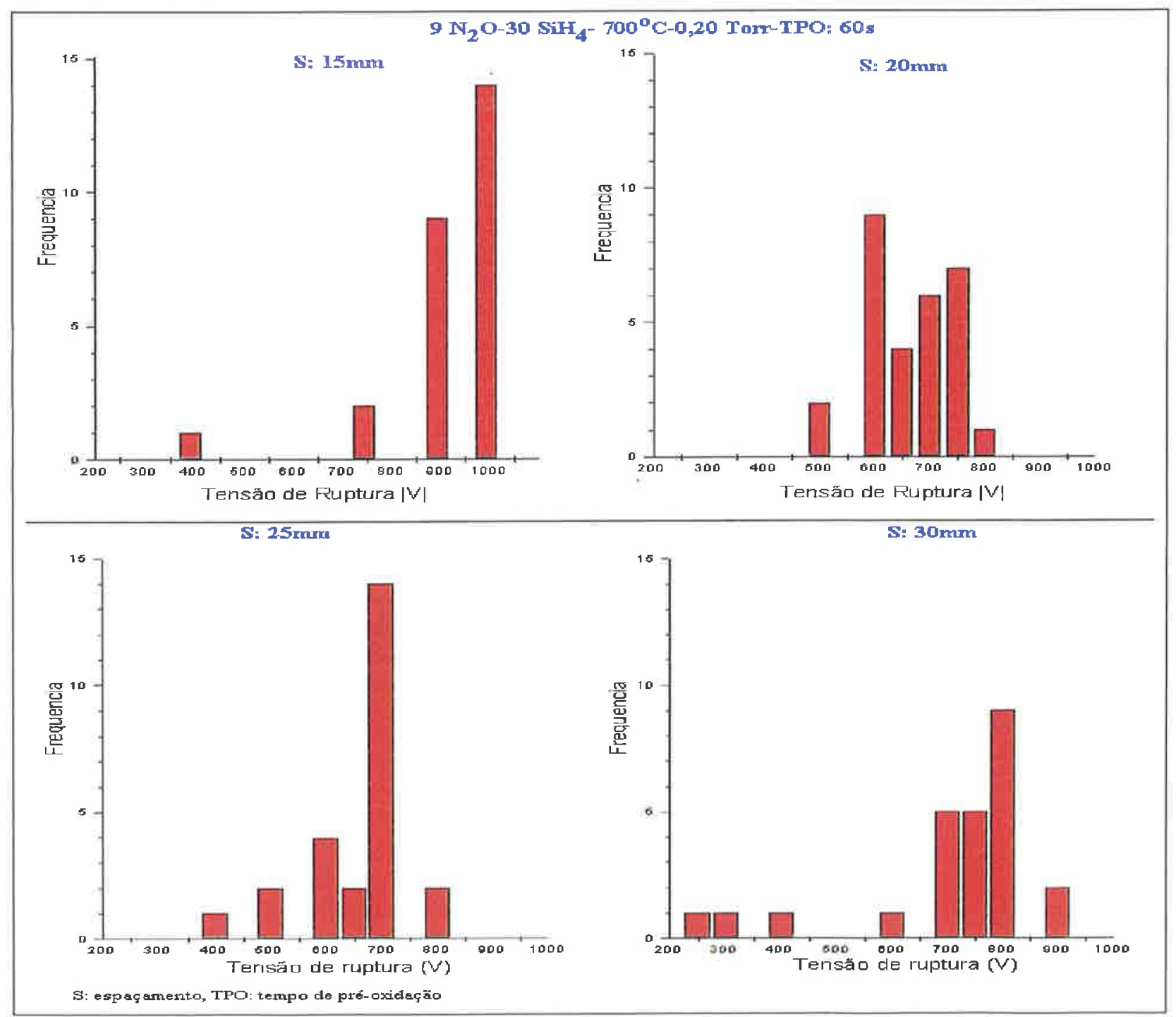

Figura 21. Histogramas do processo de passivação dos diodos de potência na qual mantivemos fixo o TPO em 60s e variamos o espaçamento entre as lâminas 
Analisando-se a figura 21, observamos que utilizando-se espaçamentos entre as lâminas de $20 \mathrm{~mm}$ e $25 \mathrm{~mm}$, ocorreu uma centralização quanto as faixas da tensão de ruptura entre (400-800) V. Isto é decorrente de que nestes espaçamentos, os filmes depositados apresentaram uma uniformidade em espessura superior a $85 \%$ (ver figura 13 ). No histograma referente ao espaçamento de ( $\mathrm{S}=15 \mathrm{~mm}$ ), a tensão de ruptura média foi de $762 \mathrm{~V}$ e uma corrente reversa de $2,56 \pm 0,23 \mathrm{~mA}$. Aumentando-se o espaçamento $(\mathrm{S}=$ $20 \mathrm{~mm}$ ), observamos uma pequena diminuição tanto da tensão de ruptura de $670 \mathrm{~V}$ como da corrente reversa para 2,23 $\pm 0,19 \mathrm{~mA}$. Já para histograma correspondente ao espaçamento de $(S=25 \mathrm{~mm})$, os valores encontrados foram de $608 \mathrm{~V}$ e uma corrente reversa de $9,51 \pm 0,58 \mathrm{~mA}$. Finalmente, para $(\mathrm{S}=30 \mathrm{~mm}$ ), a tensão média suportada nos diodos foi de $587 \mathrm{~V}$ associada a uma corrente de 11,88 $\pm 0,33 \mathrm{~mA}$. Com base nestes resultados, observamos que utilizando-se um espaçamento de $20 \mathrm{~mm}$ ocorre uma diminuição tanto da tensão de ruptura média, como da corrente reversa.

Na figura 22 verificamos o comportamento do coeficiente de variação (CV) em função do espaçamento entre as lâminas de processo em relação aos valores da tensão de ruptura reversa e da corrente reversa nos diodos de potência.

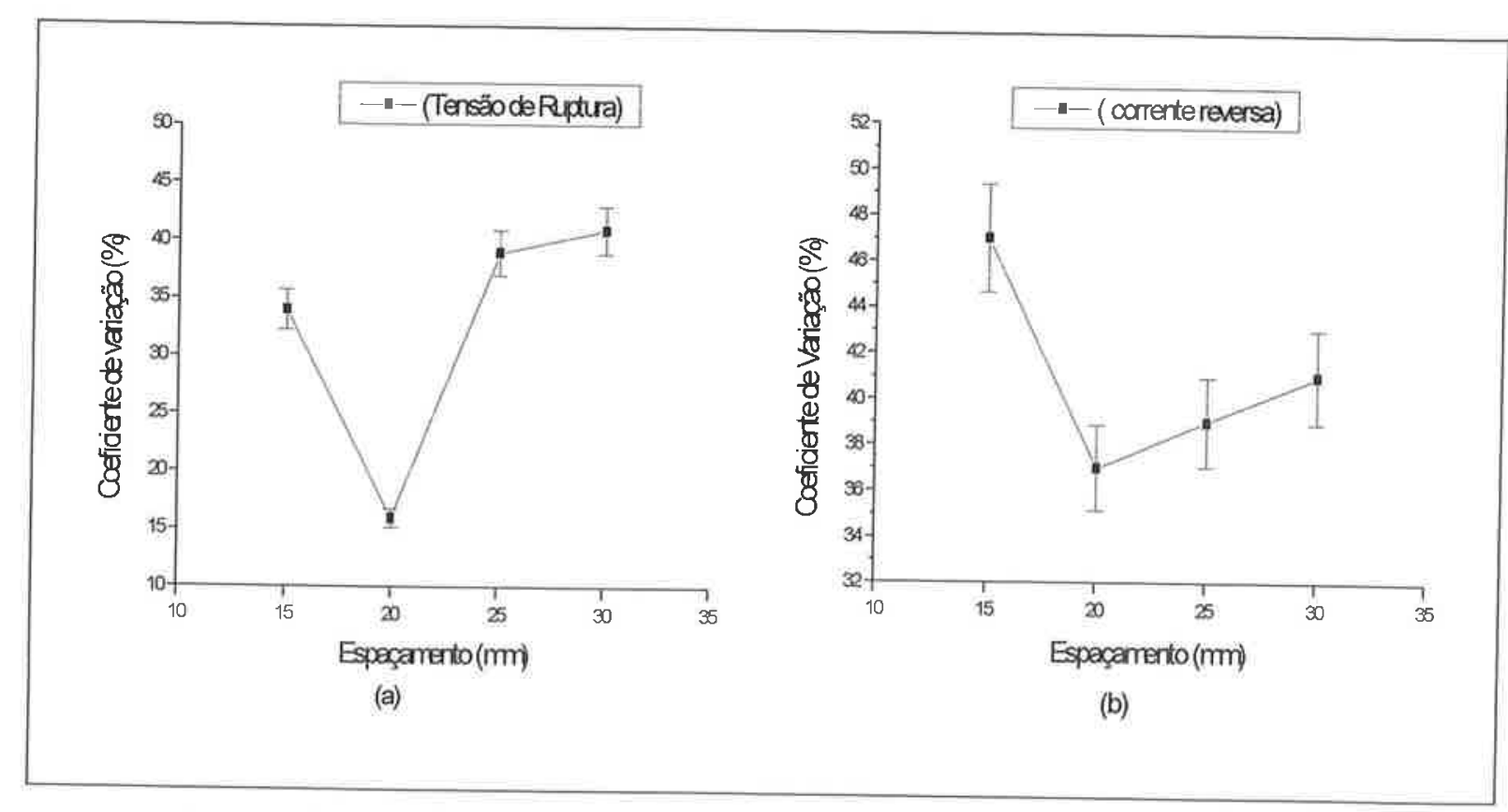

Figura 22. Coeficiente de variação em função do espaçamento entre as lâminas: a) tensão de ruptura; b) corrente reversa 
Observamos na figura 22 , que a menor variação tanto da tensão de ruptura como da corrente reversa foi encontrada quando utilizamos um espaçamento de $20 \mathrm{~mm}$. Neste espaçamento obtivemos uma variação de $16 \%$ nos valores da tensão de ruptura e uma variação de $34 \%$ na corrente reversa.

Através das figuras 21 e 22, chegamos a conclusão de que o espaçamento de $20 \mathrm{~mm}$ acarretou em uma melhora significativa no desempenho elétrico dos diodos de potência. Os resultados encontrados mostram que é possível melhorar a qualidade dos filmes depositados e por conseguinte aumentar o desempenho dos dispositivos através da determinação de um espaçamento entre as lâminas de processo.

Em decorrência da corrente reversa ainda estar relativamente elevada, procuramos através da variação do tempo de pré-oxidação reduzir a sua intensidade. Na figura 23 apresentamos o comportamento elétrico dos diodos de potência em função do tempo de pré-oxidação.

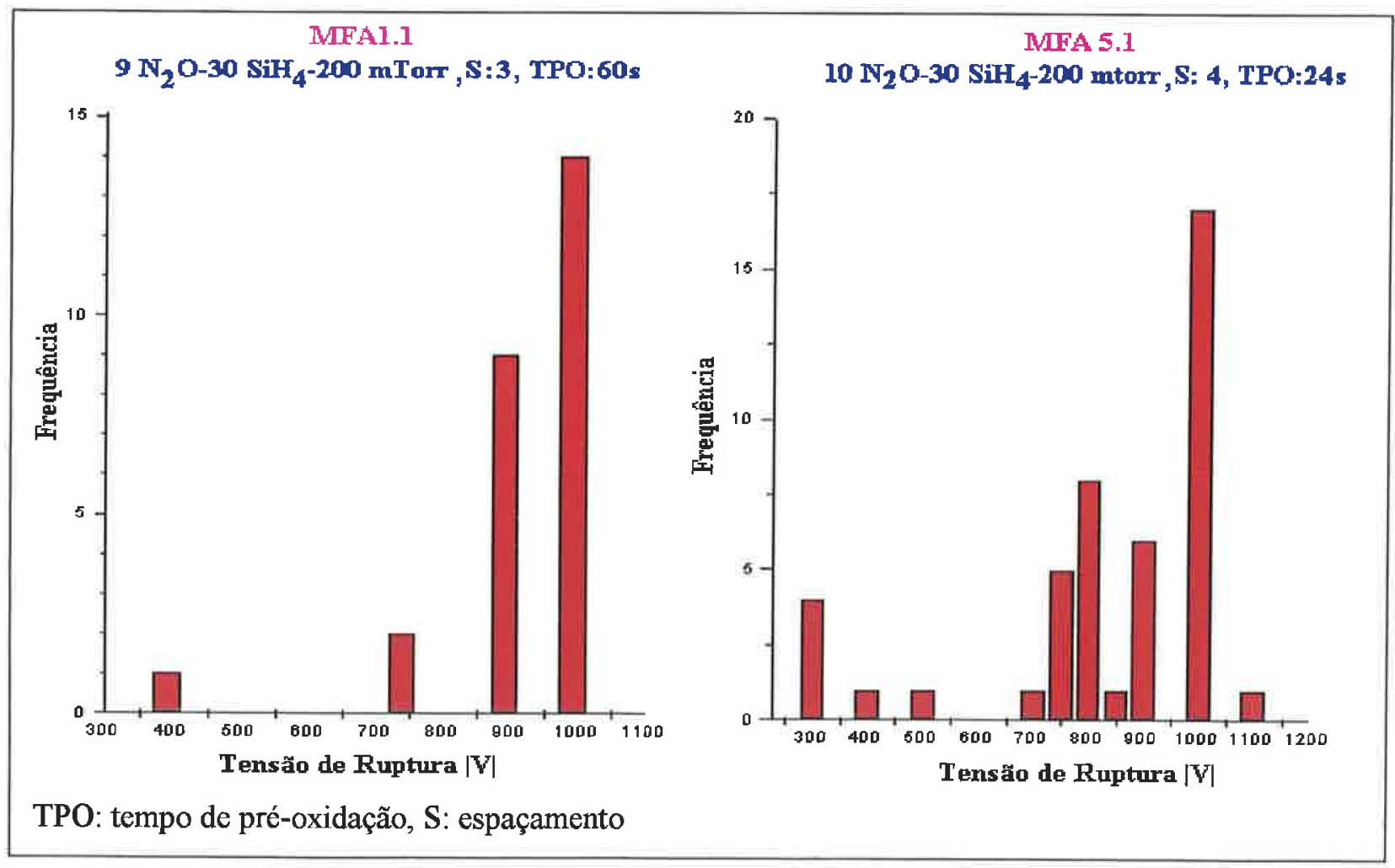

Figura 23. Histogramas dos diodos de potência na qual variamos o TPO em $60 \mathrm{~s}$ e $24 \mathrm{~s}$

Verificamos na figura 23, que com a diminuição do tempo de pré-oxidação, temos uma menor corrente reversa que circula pelo diodo de potência. A corrente reversa média 
nos diodos na condição MFA1.1 foi de 2,56 $\pm 0,23 \mathrm{~mA}$ e uma tensão de $762 \mathrm{~V}$. Entretanto com a diminuição do tempo de pré-oxidação (TPO), na condição MFA5.1 obtivemos os seguintes valores médios: tensão de ruptura de $720 \mathrm{~V}$ e corrente reversa de 2,16 $\pm 0,16 \mathrm{~mA}$. Observamos que diminuindo-se o TPO ocorreu uma diminuição da intensidade da corrente reversa da ordem de $15 \% .{ }^{[1],[19]}$ Uma explicação para a diferença quanto aos valores da corrente reversa, pode estar relacionada ao comportamento da região depletada de cargas próximo a camada de interface $\mathrm{SIPOS}-\mathrm{SiO}_{2}-\mathrm{Si}$. Isto porque as cargas armadilhadas encontradas próxima nesta região de interface contribuem para o aumento da corrente reversa. ${ }^{[13]}$

Com base nos resultados apresentados, podemos dizer que a melhor condição de deposição para o filme SIPOS para a passivação dos diodos de potência foi obtida no experimento MFA5.1. Neste experimento utilizamos uma razão gasosa de 0,30, uma pressão de 0,20 Torr, espaçamento entre as lâminas de $20 \mathrm{~mm}$ e tempo de pré-oxidação de $24 \mathrm{~s}$; o que nos propiciou obter um filme passivante que atingiu em grande parte de nossas expectativas. A meta inicial de $800 \mathrm{~V}$ foi superada com esta condição de processo, visto que conseguimos obter uma alta frequência de dispositivos que suportaram tensões reversas de até $1.100 \mathrm{~V}$ apesar de que a corrente reversa ainda é elevada.

Desta forma, repetimos este processo de deposição (MFA 5.1) durante três vezes mantendo-se os mesmos parâmetros de processo descritos. $\mathrm{O}$ objetivo deste procedimento é a de avaliar se esta condição otimizada de processo de passivação dos diodos de potência preserva suas propriedades físicas elétricas.

Na figura 24 exibimos o comportamento elétrico dos dispositivos desta condição de processo otimizada. 


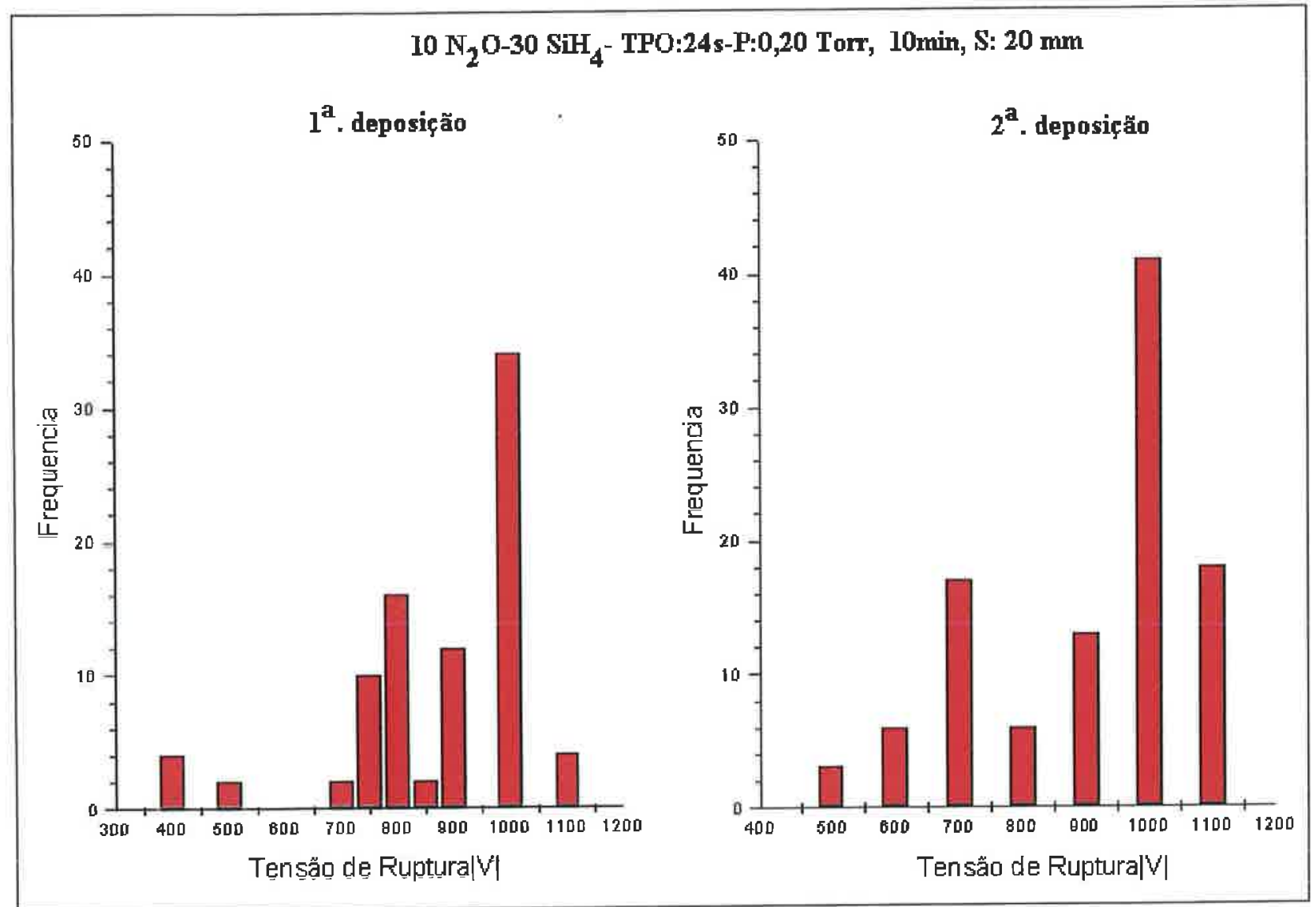

Figura 24. Comportamento elétrico dos diodos de potência mantendo-se os mesmos parâmetros de processo representado pela amostra MFA5.I.

Na figura 24 observamos que no primeiro processo obtivemos os seguintes valores: a tensão reversa média foi de $777 \mathrm{~V}$ e uma corrente reversa de $2,22 \pm 0,16 \mathrm{~mA}$. Já no segundo processo, os valores médios foram: tensão de ruptura de $800 \mathrm{~V}$ e corrente de 2,46 $\pm 0,24 \mathrm{~mA}$. Em ambos processos, observamos uma elevada frequência de dispositivos que suportaram tensões reversas superiores a $800 \mathrm{~V}$. Em virtude da proximidade dos valores médios e do comportamento da proporção da frequência de dispositivos em cada faixa de tensão apresentamos apenas dois processos.

\subsubsection{O efeito da umidade no desempenho elétrico dos diodos de potência}

Durante a caracterização elétrica dos dispositivos de potência observamos uma instabilidade elétrica da curva reversa IxV quando estes dispositivos eram submetidos à um potencial. Como mencionamos no item 4.3 o filme SIPOS é permeável à umidade ${ }^{[3],[13]} \mathrm{e}$ à contaminação iônica $^{[19]}$; o que afeta diretamente o desempenho elétrico dos dispositivos de 
potência. A solução para prevenir estes efeitos que degradam o dispositivo seria através da deposição sobre o filme SIPOS, de uma camada de nitreto de silício e sobre estas duas camadas uma terceira camada de óxido de silício. A camada de nitreto de silício impede a ocorrência da migração de íons para o filme passivante e a camada de oxido de silício funciona como uma camada de isolação.

Assim sendo, a maneira encontrada para diminuir os efeitos causados pela umidade na superfície dos diodos de potência passivados com o filme SIPOS, foi de inserir as amostras contendo estes dispositivos em uma estufa à $120^{\circ} \mathrm{C}$, durante 15 minutos.

Na figura 25, comparamos o comportamento da corrente reversa e da tensão de ruptura dos diodos passivados com a condição MFA 5.1, após a realização da etapa de aquecimento dos mesmos.

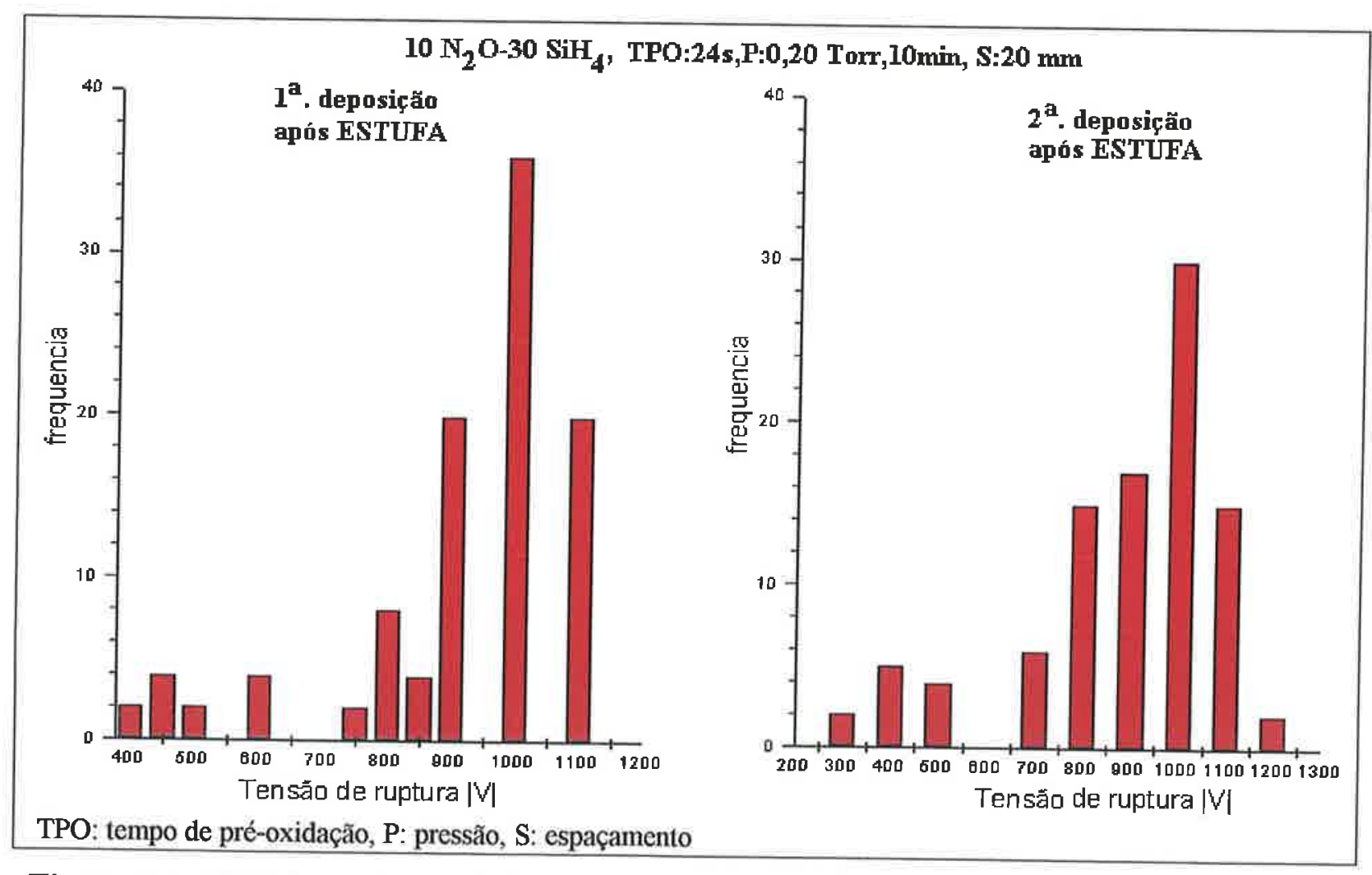

Figura 25. A influência da umidade nas características elétricas dos diodos de potência.

Através da figura 25, no primeiro processo, a tensão reversa média foi de $735 \mathrm{~V}$ e uma corrente reversa de $3,44 \pm \mathrm{mA}$. Já no segundo processo obtivemos uma tensão de ruptura de $766 \mathrm{~V}$ e corrente de 4,10 $\pm 0,51 \mathrm{~mA}$. Comparando-se o desempenho elétrico dos diodos, antes e após a realização de cada processo em estufa, podemos verificar que 
ocorreu uma diminuição gradativa dos valores das tensões reversas. De modo análogo, observamos um aumento dos valores das correntes reversas após realizado o processo em estufa. Uma explicação para a diminuição do desempenho elétrico dos diodos pode estar relacionado ao fato de que estes dispositivos entraram em processo de degradação elétrico.

Ainda na figura 25, após o aquecimento das amostras em estufa, obtivemos um aumento significativo quanto à proporção de diodos que suportaram uma tensão de ruptura compreendida entre $900 \mathrm{~V}$ e 1.100 V. Desta forma, verificamos que os diodos de potência quando expostos ao ambiente sem nenhuma camada de proteção sobre os mesmos, sofrem forte influência da umidade.

Finalmente na figura 26, apresentamos algumas curvas IxV reversas típicas dos diodos de potência que foram passivados com o filme SIPOS.

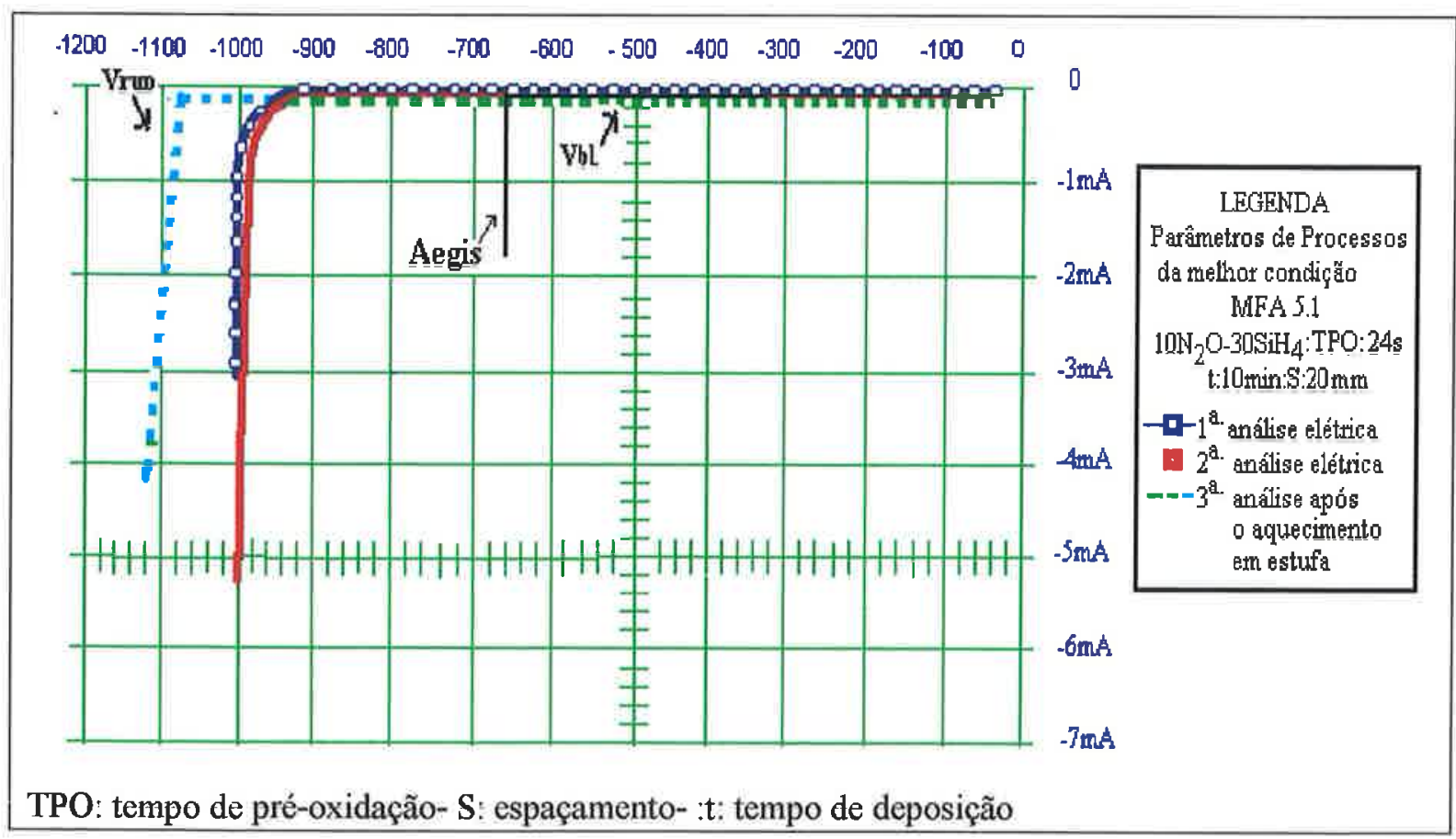

Figura 26. Curvas reversas IxV características dos diodos de potência passivados como filme SIPOS.

Nesta figura, podemos identificar as duas componentes das tensões reversas encontradas na caracterização elétrica dos diodos. A primeira componente é a tensão de bloqueio representado na figura 26 pela sigla $\left(\mathrm{V}_{\mathrm{b}}\right)$, é definida como sendo o potencial onde o diodo começa a conduzir. A segunda componente é a tensão reversa de ruptura 
representada nesta figura pela sigla $\left(\mathrm{V}_{\mathrm{rp}}\right)$, definida como o potencial pelo qual o dispositivo é submetido e onde o diodo é efetivamente danificado. Também observamos nesta figura a curva IxV característica dos diodos de potência fornecidos pela Aegis Ltda.

Comparando-se as curvas reversas ( $\mathrm{IxV}$ ) dos diodos de potência passivados com o filme SIPOS com a da Aegis, claramente observamos um aumento da tensão de ruptura reversa da ordem de aproximadamente $70 \%$. Além disso, podemos verificar que perfil das curvas reversas $\mathrm{IxV}$ tornam-se mais abruptos após os diodos de potência terem sido submetido ao processo em estufa. Isto indica que o filme SIPOS depositado sofre forte influência da umidade, encontrada no ambiente externo; o que contribui para a degradação elétrica do dispositivo.

\subsection{Conclusões Finais}

Inicialmente verificamos a influência dos parâmetros de processos do sistema LPCVD (pressão, razão gasosa $\left(\mathrm{N}_{2} \mathrm{O} / \mathrm{SiH}_{4}\right)$, espaçamento entre as lâminas de processo e o tempo de camada de pré-oxidação) para a obtenção de uma filme de silício policristalino dopado com oxigênio visando sua aplicação como camada de passivação em dispositivos de potência.

Através da caracterização dos filmes por elipsômetria, verificamos que a taxa de deposição não apresenta uma variação significativa com o aumento da pressão de processo. Experimentalmente podemos verificar que os espaçamento entre as lâminas no reator LPCVD de $20 \mathrm{~mm}$ e $25 \mathrm{~mm}$, propiciaram a obtenção de filmes com uma maior uniformidade em espessura.

Através dos espectros de RBS, verificamos que os filmes que continham uma menor concentração de oxigênio foram encontrados quando utilizamos um espaçamento de $20 \mathrm{~mm}$ e com baixa proporção gasosa de $\left(\mathrm{N}_{2} \mathrm{O} / \mathrm{SiH}_{4}\right)$.

Relacionando-se os resultados obtidos pelas análises por RBS e FTIRS, podemos concluir que o espaçamento entre as lâminas afeta diretamente as propriedades dos filmes depositados.

Analisando-se os espectros FTIRS das amostras depositadas, podemos identificar a presença das ligações químicas Si-O-Si presente nas duas pressões de processo. 
Baseando-se no modelo proposto por $\mathrm{Ni}$ e Arnold, podemos verificar que a condutividade elétrica do filme SIPOS decresce com o aumento da proporção gasosa entre $\left(\mathrm{N}_{2} \mathrm{O} / \mathrm{SiH}_{4}\right)$. Entretanto, não observamos um aumento significativo da condutividade com o aumento da pressão de processo.

Observamos através dos histogramas das medidas de tensão de ruptura dos diodos de potência, que a pressão de processo e a razão gasosa influem no desempenho elétrico dos diodos de potência. Com o aumento destes parâmetros de processos temos uma diminuição significativa da tensão de ruptura e um aumento da corrente reversa nos dispositivos de potência.

Portanto, com base nestes resultados apresentados neste trabalho, chegamos a conclusão de que o melhor processo de passivação dos diodos de potência foi o experimento MFA5.1. Neste experimentos utilizamos a temperatura de $700^{\circ} \mathrm{C}$, razão gasosa $\left(\mathrm{N}_{2} \mathrm{O} / \mathrm{SiH}_{4}\right)$ de 0,30 , pressão de 0,20 Torr, espaçamento entre as lâminas de $20 \mathrm{~mm}$ e tempo de pré-oxidação de $24 \mathrm{~s}$. Através destes parâmetros de processos, conseguimos aumentar o desempenho elétrico dos diodos de potência para tensões de rupturas superiores a $1.000 \mathrm{~V}$.

\section{Experimentos Futuros}

Com base nos resultados encontrados neste trabalho, apresentamos a seguir algumas sugestões para experimentos futuros:

a) após realizar a limpeza química padrão de todas as lâminas de silício, seria interessante verificar a presença de contaminantes metálicos na superfície da lâminas. Através desta técnica é possível detectar a presença de contaminantes metálicos na superfície das lâminas de silício.

b) fabricar capacitores MSS com menores dimensões, por exemplo (300 $\mu \mathrm{m}$ x 300 $\mu \mathrm{m})$, para determinar a densidade de cargas efetivas no filme SIPOS. Deseja-se que esta densidade de cargas no filme seja baixa, para favorecer o relaxamento da região de depleção próximo a interface SIPOS-Si. Deste modo, o campo elétrico superficial será 
menor e por conseguinte maior a tensão de ruptura suportada pelo dispositivo.

c) determinado o melhor processo de deposição do filme SIPOS, depositar sobre o filme SIPOS uma camada de nitreto de silício e uma segunda camada de óxido de silício.

d) a partir da determinação de melhores condições de processo de deposição do filme SIPOS seria interessante implementar testes de confiabilidade e de durabilidade para que o processo possa ser inserido em uma linha de produção. 


\section{Anexo 1: Modelamento matématico proposto por Ni e Arnold}

A densidade de corrente de tunelamento da rede é ${ }^{[42]}$

$$
J=4 \cdot \pi \cdot e \cdot \frac{m}{h^{3}} \int D\left(E_{X}\right) d E_{X} \int\left[f(E)-f\left(E+e V_{S i O 2}\right) d E_{Y Z} \cdot \text { Equação } 1\right.
$$

onde $\mathrm{f}(\mathrm{E})$ é o nível de Fermi, $\mathrm{D}(\mathrm{Ex})$ é a probabilidade de transmissão da barreira na direção do eixo $\mathrm{x}, \mathrm{m}$ é a massa efetiva do portador no silício, e $\mathrm{V}_{\mathrm{SiO} 2}$ é a polarização que surge nas camadas de óxido entre os grãos. Os limites de integração se estendem desde o nível da banda de condução do silício até os níveis energéticos mais altos. Utilizando a aproximação de WKB (Wentzel-Kramers-Brillouin ${ }^{[42]}$ ) para tunelamento em baixos campos elétricos, a probabilidade de transmissão será:

$$
D=\exp \left[-2 \cdot \pi \frac{\sqrt{8 \cdot m_{e} \cdot q \cdot \phi}}{h} \cdot t_{\text {SiO2 }}\right]
$$

Equação 2

onde: $\phi$ é a altura da barreira em elétrons-volts e me é a massa efetiva do elétron na camada de óxido. Deste modo a densidade de corrente será ${ }^{[43]}$

$$
J=\left(4 \cdot \pi \cdot q^{2} \cdot m \cdot \frac{k \cdot T \cdot V_{\text {SIOL }}}{h^{3}}\right) \cdot \exp \left(\frac{q \cdot E g}{2 \cdot k \cdot T}\right) \cdot \exp \left[2 \cdot \pi \frac{\sqrt{8 \cdot m_{e} \cdot q \cdot \phi}}{h} \cdot t_{\text {SiOZ }}\right] . \text { Equação } 3
$$

onde: Eg é a energia entre a banda de condução e a de valência do silício, $\mathrm{k}$ é a constante de Boltzmann, h é a constante de Planck, T é a temperatura em Kelvin, e q é a 
carga do elétron. Sendo que este resultado é válido para pequenos campos elétricos, podemos fazer a seguinte aproximação: ${ }^{[28]}$

$$
f(E)-f(E-e V) \cong-q V \frac{\partial f(E)}{\partial E} . \quad \text { Equação } 4
$$

Para determinarmos a condutividade do filme SIPOS $(\sigma)$ teremos de dividir a densidade de corrente no filme (J) pelo campo elétrico médio no filme (F), que é :

$$
F=\frac{\left(V_{S i}+V_{S i O 2}\right)}{\left(x_{S i}+t_{S O 2}\right)} . \quad \text { Equação } 5
$$

onde: $V_{\mathrm{Si}}$ é o potencial no grão de silício, $\mathrm{x}_{\mathrm{si}}$ é a distância entre cada grão de silício, $t_{\mathrm{SiO} 2}$ é espessura do filme e $v_{\mathrm{SiO} 2}$ é o volume do filme depositado. A voltagem $\mathrm{V}_{\mathrm{Si}}$ é determinada pela condutividade dos grãos de silício intrínseco, e deste modo a densidade de corrente pode ser escrita como :

$$
J_{\text {grđo }} \cong 2 \cdot\left(\frac{2 \cdot \pi \cdot m_{e} \cdot k \cdot T}{h^{2}}\right)^{3 / 2} \cdot\left(\frac{e \cdot \mu_{n} \cdot V_{s i}}{x_{s i}}\right) \cdot \exp \left(-\frac{E g}{2 \cdot k T}\right) \quad \text { Equação } 6
$$

sendo: $\mu_{\mathrm{n}}$ a mobilidade dos elétrons nos grãos de silício. Se combinarmos as equações 2 e 5 veremos que:

$$
\frac{V_{\mathrm{a}}}{V_{\mathrm{SO} 2}} \cong\left(2 \cdot \pi \cdot m_{a} \cdot k \cdot T\right)^{-1 / 2} \cdot\left(\frac{e \cdot x_{\mathrm{s}}}{\mu_{n}}\right) \cdot \exp \left[-2 \cdot\left(\frac{8 \cdot \pi^{2} \cdot m_{e} \cdot q \cdot \phi}{h^{2}}\right)^{1 / 2} \cdot t_{\mathrm{SO} 2}\right]<<1 \text {.Equação } 7
$$


deste modo quase toda a polarização recai sobre a camada de óxido entre os contornos de grão e, a condutividade do filme SIPOS será :

$$
\sigma=4 \cdot \pi \cdot q^{2} \cdot m \cdot \frac{k \cdot T \cdot\left(x_{s i}+t_{s K Q}\right)}{h^{3}} \cdot \exp \left(\frac{q \cdot E g}{2 \cdot k \cdot T}\right) \cdot \exp \left[2 \cdot \frac{\sqrt{8 \cdot \pi^{2} \cdot m_{e} \cdot q \cdot \phi}}{h} \cdot \delta_{\text {sią }}\right] \cdot \text { Equação } 8
$$

Atribuindo-se as constantes A e B na equação 8, obtemos :

$$
\begin{aligned}
& A=\frac{4 \cdot \pi \cdot q^{2} \cdot m \cdot K \cdot T}{h^{3}} \cdot \exp \left(\frac{q \cdot E g}{2 \cdot k \cdot T}\right) \\
& B=2 \cdot \frac{\sqrt{8 \cdot \pi^{2} \cdot m e \cdot q \cdot \phi}}{h}
\end{aligned}
$$

Equação 9

Consequentemente, a condutividade elétrica no filme SIPOS é :

$$
\sigma_{\text {média }}=A \cdot\left(x_{S i}+t_{s i o}\right) \cdot \exp \left(-B \cdot t_{s i O}\right) \quad \text { Equação } 10
$$




\section{Anexo 2 :Análise por RBS}

A reta de calibração foi determinada através do método de energia incidente constante $\left(\mathrm{E}_{\mathrm{o}}\right)$ variando-se o tipo do alvo. Os alvos utilizados para determinarmos esta reta de calibração foram: o ouro, o cobalto e o silício.

Aplicando-se sobre os alvos citados uma mesma energia incidente $(1,2 \mathrm{MeV})$, obtemos um valor de canal correspondente para cada alvo ( $\mathrm{Au}, \mathrm{Co}$ e $\mathrm{Si}$ ). Desta forma, conhecendo-se o tipo do alvo, a energia incidente e o ângulo de incidência do feixe incidente, determinamos o fator cinemático $\left(\mathrm{K}_{\mathrm{o}}\right)$, pois sabemos que estes elementos estão na superficie do substrato. Assim sendo, a energia retroespalhada $\left(E_{1}\right)$ pode ser calculada pela seguinte expressão :

$$
E_{1}=k_{\text {alvo }} \cdot \text { Eo } \quad \text { Equação I }
$$

E através da regressão linear, determinamos a seguinte reta de calibração :

$$
E_{1}=x \cdot y+C \quad \text { Equação 2, }
$$

,onde x é a largura do canal $\left(\Delta \mathrm{E}_{\mathrm{c}}\right)$ e $\mathrm{C}$ é o 'offset'.

Para determinarmos a taxa de incorporação de oxigênio presente nos filme depositados, utilizamos a aproximação da superfície; equação 3 :

Admitindo-se que no espectro por RBS, a altura do oxigênio seja $2,5 \mathrm{~cm}$ e que a altura do silício seja $6,1 \mathrm{~cm}$ e conhecendo-se o número atômico do oxigênio (8) e do silício (14) então chegamos a equação 4 :

$$
x=\frac{H_{o}}{H_{S i}} \cdot \frac{\left(Z_{o}\right)^{2}}{\left(Z_{S i}\right)^{2}} \quad \text { Equação3 }
$$

Logo a taxa de concentração de oxigênio no filme SIPOS será :

$$
O(\%)=\frac{x}{1+x} .100 \quad \text { Equação } 4
$$




\section{Referencias Bibliográficas}

[1] Baliga, B. Jayant Power Semiconductor Devices, PWS Publishing Company, 1996

[2] Sze, S. M. Physics of Semiconductor Devices; A Wiley-Interscience Publication Inc. (1976).

[3] T. Matsushita, T. Aoki, T. Ohtsu and other, IEEE Trans. Electron Devices. Vol ED 23, no. 8 pg 826-830, ( 1976)

[4] Wolf, S. e Tauber, R. N. Silicon Processing for the VLSI Era: Process Tecnology Sunset Beach, Lattice Press, v. 1 (1986).

[5] K.Miwa, M. Kanno, S. Kawashima and other, 'Glass passivation of silicon devices by electrophoresis' Denki Kagaku, vol. 40, pp. 478-484 (1972)

[6] C. A. Neugebauer, J. F. Burgess, R. E. Joynson and J.L. Mundy, J Appl. Phys.Letters. Vol. 19, p. 287 (1971).

[7] Ben G. Streetman, 'Solid State Eletronic Devices' fourth edition

[8] DiMaria, D. J. and other,'Charge Transport and trapping phenomena in offstoichiometric silicon dioxide films', J. Appl.Phys. .54 (10),p. 5801-5827(1983)

[9] R.R.Verderber, G. A. Gruber and other, ' $\mathrm{SiO}_{2} / \mathrm{Si}_{3} \mathrm{~N}_{4}$ passivation of high power retifiers'; IEEE Transactions on Electron Devices, vol. Ed -17, pp 797-799 (1970)

[10] D.Jaume, and other,' High Voltage Planar Devices Using Field Plate and SemiResistive Layers', IEEE Transaction on Electron Devices, Vol. ED 38 № 7, july (1991).

[11] Brüesch, P.; Stockmeier, Th.; e Stucki, F. 'Physical Propertiers of Semi-Insulating Polycrtstalline Silicon. I. Structure, Eletronic Propertiers, and Electrical Conductivity'; J. Appl. Phys. Vol. 73 №. 11, p. 7677-7689, (1993).

[12] F.P.Fehlner, W.H. Dumbaugh and R.A. Miller, Japan Displays 1986 (Society for Information Displays, Playa del Rey, CA, 1986),pp 200-203.

[13] Burte, E. P.' Interface Trap Density near Midgap of SIPOS Films Deposited on Crystalline Silicon'; J. Electrochemical Soc., Vol. 135, № . 4, p. 1017-1019, 1988.

[14] T. Matsushita, and other, Apply Physics Letters. Vol 35, no. 7 pg 549-550,( 1979 
[15] Biay-Chieng Hseih, Miltiadis K. Hatalis,'Low Temperature Polycrystaline Silicon Thin Film Trsnsitors for Displays', IEEE Trans. Electron Devices. Vol ED 35, no. 11, november ( 1988)

[16] Garrido,B. e outros, 'Structure and photoluminescense of anneling semi-insulating polycrystalline silicon obtain by disilane', Elsevier, Thin Solid Films 296, p. 98-101(1977)

[17] Yablonovitch, E. Gmitter, T. " A 720mV open circuit voltage SiOx:c Si:SiOx double heterostructure solar cell "Appl. Phys. Lett. 47(11) p.1211-1213 (1985)

[18] R. Hezel and K. Jaeger, J.Electrochemical Soc., 125,1723(1978)

[19] Edmund P, Burte; 'On the blocking behaviour of mesa high voltage power devices passivated by semi-insulating polycristalline silicon films', Thin Solid Films, 168 (1989) 41-50.

[20] N. Nagasima and N. Kubota, Jpn J. Appl. Physics 14, 1105 (1975)

[21] T.I.Kamins, M. M. Mandurah and K.C. Saraswat; J. Electrochemical Soc., 125,927 (1978).

[22] T.I.Kamins, and K.L. Chiang ; J. Electrochemical Soc., 129,2326 (1982)

[23] Greenberg, B. e Marshall, T. 'The Volume Fraction of Crystalline Silicon in SemiInsulating Polycrystalline Silicon (SIPOS)', J. Electrochemical Soc. - Solid State Science and Technology, Vol. 135, №. 9, p. $2295-2298$ (1988).

[24] Cordier, C., Dehan, E., Scheid, E., e Duverneuil P. ' Semi-insulating propertiers control by CVD process modeling ': Elsevier Science S.A p. $30-34$ (1996)

[25] Andrew Yeckel and Stanley Middleman, 'The Origin of Nonuniform growth of LPCVD films from silane gas mixtures', J. Eletrochemical Soc. Vol. 135, $\mathrm{n}^{\circ} .7(1989)$

[26] Sandoes, J. N., Hughes, J. R. e Slatter, J. A. G. 'Characterisation and modelling of SIPOS on silicon high-voltage devices', IEEE Proceedings, Vol. 132, Pt. I № 6, p. 281284, (1985)

[27] Joubert .P and others. 'The effect of low pressure on the structure of LPCVD polycrystalline silicon films'. J. Eletrochemical Soc. Vol. 134, $\mathrm{n}^{\circ} .10,(1987$ )

[28] Ni, J. e Arnold, E.' Electrical conductivity of semi-insulating polycrystalline silicon and its dependence upon oxygen content', J. Appl. Phys. Lett. Vol. 39 (7), p. 554 - 556 (1981). 
[29] H. Mochizuki, T. Aoki, H. Yamoto and others, Jpn. J Appl. Phys. Suppl. Vol. 15, p. $41(1976)$.

[30] Stengl, P. e Falck, E. 'Surface Breakdown and Stability of High Voltage Planar Junctions', IEEE Trans. on Electron Dev., Vol. 38, № 9, p. 2181 - 2188 (1991

[31] J. van den Broek, Philips Res. Rep., 22,367(1967)

[32] Hitoshi Kume, 'Métodos estatísticos para melhoria da qualidade', Editora Gente, 1993

[33] W.J. Bertram, VLSI Technology, Yield and Reliability, cap 14, pag 599-639

[34] Maissel, L. I.; Glang, R. Handbook of Thin Film Tecnology. In Campbell, D. S. Mechanical Properties of Thin Films. New Work, Mac Graw-Hill, 1970

[35] John Pike and Richard Barnes, TQM in action, Ed. Chapman \& Hall, 1994

[36] Irving W. Burr, Engineering Statistics and Quality Control, Mc Graw Hill-1953

[37] T. Aoki, T. Matsushita and others, Electrochemical Society Extend. Abstracts, 75 (1) (1975) 352

[38] D. Iosif, V. Soltuz and G. Dinoiu, Thin Solid Films, 75 (1981) 125-131

[39] Simon S., Ang, IEEE Trans. Electron Devices. Vol ED 35, no. 8, pg 1378-81, Ago (1988)

[40] Verstengen, B.;Habraken,F.H.P.M. e Van Der Weg W.F 'The role of hydrogen in the deposition, composition, and structure of semi insulating polycristalline silicon films'; J.Appl.Phys. Vol 57 no 8, pg 2766-2770 (1985)

[41] Ferreira, Eduardo dos Santos; 'Estudo e caracterização de filmes SIPOS para a passivação de dispositivos de potência' Dissertação de mestrado, EPUSP São Paulo, 2000.

[42] C.B.Duke, Tunneling in Solids (Academic, New Work, 1969), Chap.4

[43] M. Lenzlinger and E.H. Snow, J. Apply Physics, Vol. 40, pg 278, (1969) 
